\title{
El beato Marcelo Spínola y Maestre: Su modo particular de presentar el sacerdocio
}

\author{
Marcelo Spinola y Maestre and his \\ particular approach to priesthood
}

\author{
Amador Domínguez Manchado \\ Párroco de San Francisco de Asís de Sevilla \\ Profesor de la Facultad de Teología San Isidoro de Sevilla
}

https://orcid.org/0000-0002-1860-0077

Resumen: Estudio de la originalidad del sacerdocio del beato Marcelo Spínola y Maestre, para el cual nos servimos de la exposición y explicación pormenorizada de distintos aspectos de su vida, obra y magisterio. Así, abordaremos el lugar central que ocupó el Corazón de Jesús en su espiritualidad y enseñanzas, así como su implicación política y social, siempre acorde al mensaje evangélico y defendiendo a la Iglesia. Para la elaboración de este artículo hemos llevado a cabo una investigación histórica en la que hemos acudido a variadas y abundantes fuentes, dando un lugar prioritario a los escritos del beato Spínola.

Palabras clave: Sacerdocio; Sagrado Corazón de Jesús; Oración; Eucaristía; Virgen de la Inmaculada Concepción; Política; Cuestión obrera; Prensa y propaganda católica; Senado; Unión de los católicos.
Abstract: This paper studies the originality in the approach to pristhood of Marcelo Spinola y Maestre. To accomplish this task we present and explain with detail various aspects of Spinola's life, work and teaching. Thus, we talk vastly about the importance of the Sacret Heart of Jesus in his spirituality and teaching, as well as his involvement in political and social issues during his life, in which he gave prove of his loyalty to the evangelical content and the Catholic Chuch. The methodology to elaborate this historical investigation has been the study of various and abundant bibliography, paying at the same time special attention to the material Spinola wrote himself at the time.

Keywords: Priesthood; Sacret Heart of Jesus; Prayer; Eucharist; Virgin of the Inmaculate Conception; Politics; Working class issue; Press and catholic propaganda; Senate; Unite the catholics.

\section{INTRODUCCIÓN}

Nos proponemos con este estudio argumentar de forma adecuada la originalidad de Spínola, presentando su modo particular de ejercer su sacerdocio. 
Nuestro personaje no dejó nunca de preocuparse por aquellos asuntos que se refieren al desarrollo íntegro del hombre y de la sociedad, sobre todo, a los que afectan a los derechos y dignidad de la persona. Él era consciente de que ninguna realización temporal se identifica con el Reino de Dios, sin embargo, todas ellas pueden anticipar la gloria de ese Reino futuro y eterno que llegará después de la parusía. Esa espera, hasta entonces, significaba para nuestro autor, trabajar mediante el ejercicio del orden sacerdotal centrado en la espiritualidad del Sagrado Corazón de Jesús por la salvación de las almas, y en defensa de la Iglesia, con su implicación en la cuestión obrera, en las realidades políticas y sociales, con su intervención en la organización de la propaganda católica, de la prensa y la fundación del diario El Correo de Andalucía, así como de la Liga Católica de Sevilla, y por último, en su condición de Senador del Reino. Su celo pastoral era el impulso y la fuerza que le movía a desempeñar el sacerdocio de este modo particular, y que consideramos una originalidad.

Nosotros pretendemos exponer toda esta variedad de actividades que nuestro purpurado desarrolló desde su ministerio ordenado; y que eran un fiel reflejo de su vida interior, de su espiritualidad; que tenían como base una vida ordenada y metódica; cuya única pretensión al realizar todas estas actividades, era defender los derechos de los cristianos y de la Iglesia de Jesucristo. Por todo ello, creemos, que del desempeño de todas estas formas de ejercer el ministerio sacerdotal, podemos sacar como consecuencia, unos cánones pastorales, que pueden servir de enseñanza para el actuar de los sacerdotes en su ministerio, convirtiéndose en una fuente de formación para el clero.

\section{UNA ESPIRITUALIDAD CENTRADA EN EL CORAZÓN DE JESÚS}

\subsection{Una devoción omnipresente y permanente en su vida}

La espiritualidad de don Marcelo, su doctrina, vivencias y virtudes, que forman un entramado de fuertes conexiones con un sentido lógico: el deseo constante desde niño de la santidad, la profunda vida de oración, la humildad, la austeridad, la devoción a la Eucaristía y a la Virgen, el celo pastoral y el amor al prójimo (especialmente a los más pobres e indefensos). A nuestro parecer, el Corazón de Jesús es el centro de toda su vida interior y el motor de toda su actividad pastoral; no importa la virtud que se considere; estamos seguros de que 
tiene su conexión con el Corazón de Jesús. Podemos asegurar, que nuestro personaje pretendió ser siempre, una copia fiel del Sagrado Corazón de Jesús: "Dichosos nosotros si pudiéramos a Él asemejarnos, y nos fuera dado caminar, siquiera de lejos detrás de Jesucristo"1. La centralidad de su vida en esta devoción queda testimoniada en el siguiente texto:

“¿Quién que versado se halle, o lo menos iniciado en la ciencia de lo sobrenatural, no se ha figurado el Corazón de Jesús como un astro incomparable? Rey de todos los astros, soberano de todos los soles, jefe de todas las nebulosas, en derredor del cual todo gira: la antigüedad con sus hombres, la edad moderna con los suyos, el cielo con sus ángeles, la creación estelar con sus habitantes, donde los haya; María Santísima con sus incomparables glorias y la Santísima Trinidad toda con su omnipotencia, su sabiduría infinita y su infinito amor [...] Es sin disputa,el Corazón de Jesús espectáculo más sublime que el de los espacios etéreos $[\ldots]^{\prime 2}$.

Para nuestro autor, esta devoción constituye el eje, alrededor del cual gira la identidad total del sacerdote con Cristo; por dos motivos: primero porque lo trata en su reflexión sobre el sacerdocio ministerial, y no como un apéndice, sino como elemento esencial; y segundo, porque considerando las enseñanzas expositivas, nuestro personaje, el Corazón de Jesús es el "lugar teológico" por excelencia, donde el sacerdote conoce y aprende a identificarse con Cristo Maestro, Cabeza y Pastor.

Toda su vida sacerdotal (presbítero y obispo) está llena de la presencia de esta espiritualidad cristológica; desde el primer momento que conocemos ${ }^{3}$, hasta el último ${ }^{4}$.

1 GARCÍA MARTÍN, N., Vida de Don Marcelo Spinola y Maestre, Cardenal Arzobispo de Sevilla. Fundador de las Esclavas del Divino Corazón. Apuntes de la Postulación. Estudio sistemático y cronológico de su vida, Mecanografiadas y encuadernadas a mano. En Archivo Marcelo Spínola (al que en adelante nos referiremos como AMS) C D. 2; D. 2. 1. Sevilla, 1955, cap. X, p. 16.

2 AMS Fascículo (al que en adelante nos referiremos como F.) 50, pp. 4-5.

3 En unas reflexiones que don Marcelo hace, antes de ser ordenado, sobre su vocación anota este pensamiento:

El corazón es susceptible de purificación, se purifica en el crisol de las contradicciones [...]; justo es, pues, amarlas. Se purifica en la penitencia [...], debe ser mi distintivo. Se purifica, sobre todo, en el fuego del amor divino. Para purificar, por tanto, mi corazón conviene colocarlo sobre las llamas del Corazón de Jesús. (AMS F. 66, pp. 46-47).

4 Por el otro extremo de su vida ministerial, en el último documento que escribió para el boletín del arzobispado en la misma semana anterior a su muerte, expresa a sus sacerdotes de Sevilla: 
Precisamente esta devoción, fue la que hizo coincidir la celebración de su primera misa en la fiesta del Corazón de Jesús ${ }^{5}$.

Cuando fue consagrado obispo auxiliar del cardenal Llunch, colocó en el centro de su escudo heráldico ${ }^{6}$, el Corazón de Jesús y como lema: "Omnia possum in eo".

Las tres diócesis que gobernó, al poco tiempo de llegar, las consagra a este Divino Corazón ${ }^{8}$.

También la mayoría de sus sermones, pláticas, meditaciones y recomendaciones, están llenas de referencias explícitas a esta devoción cristológica9. Hasta el extremo, llega su amor al Sagrado Cora-

Ya que otra cosa no podemos hacer, vamos a rogar con fervor centuplicado [...] al Padre de las misericordias que nos meta bien adentro en el Corazón de Jesús, morada de paz dulcísima en la que el que logra entrar se encuentra bien y a gusto.

(AMS Boletín oficial del arzobispado de Sevilla (al que en adelante nos referiremos como BOAS) 584 [1906] 6-7).

5 Cf. FERNÁNDEZ CABELlO, C., Recuerdo de la Primera Misa del Excmo. y Romo. Sr. D. Marcelo Spínola y Maestre, Arzobispo de Sevilla, Imprenta de Izquierdo y Cía., Sevilla, 1900, pp. 5-45; DE SOBRINO, J. A., El Venerable Spínola. Perfil y espíritu, BAC, Madrid, 1984, p. 27; RUIZ SÁNCHEZ, J. L., Beato Marcelo Spinola y Maestre, cardenal arzobispo de Sevilla (1835-1906), Servicio de Publicaciones del Ayuntamiento de Sevilla, Sevilla, 2002, pp. 34-35.

6 Cf. RUIZ SÁNCHEZ, J. L., "Vida y obra de Marcelo Spínola y Maestre (18351906)", en: J. M. MÁRQUEZ DE LA PLATA CUEVAS - M. MARTÍN RIEGO - J. L. RUIZ SÁNCHEZ, Marcelo Spinola. Estudios en un Centenario (1906-2006), Fundación Universitaria San Pablo CEU, Sevilla, 2006, p. 25.

7 Su lema episcopal está tomado de las Cartas de San Pablo (Flp 4,13.), y aparece en latín en la parte inferior del escudo, al interno de una banda que en español significa, "todo lo puedo en él". Es una expresión que se refiere directamente al Corazón de Cristo y que manifiesta un doble sentimiento del espíritu de nuestro beato:

La propia desconfianza, fundada en el sentimiento de su pequeñez; y la confianza plena y suma en el poder, en la virtud y en la fuerza que desde sus primeros años le comunicaba el Corazón deífico.

(GARCÍA MARTÍN, N., Vida de Don Marcelo Spínola y Maestre, Cardenal Arzobispo de Sevilla. Fundador de las Esclavas del Divino Corazón. Apuntes de la Postulación. Estudio sistemático y cronológico de su vida, Mecanografiadas y encuadernadas a mano. En AMS C D. 2; D. 2. 1., Sevilla, 1955, cap. X, pp. 380-381).

$8 \quad$ Cf. AMS BOC 332 (1885) 577-589; BOM 6 (1887) 89-113; BOAS 393 (1898) 349-381.

9 Sirva de ejemplo como dato significativo de lo que hemos dicho, el siguiente texto tomado de sus apuntes personales autobiográficos:

Realmente es el Corazón de Jesús un abismo. Jamás se llega a su fondo. Diríase que es como gigante cúpula, que domina el grandioso edificio de la Iglesia y toda la extensión de Ésta. Adonde quiera que volvamos los ojos nos lo encontramos.

(AMS F. 2, p. 18). 
zón, que se entrega totalmente a Él, consagrándose por entero, como encontramos en uno de sus escritos autobiográficos más íntimos: "Conclusión de todo. Una nueva consagración absoluta irrevocable y generosa hasta el anonadamiento al Corazón Sacratísimo de Jesús, ofreciéndonos a él por medio de María Santísima"10. Por las tres diócesis que pasó, dejó grandes muestras de esta devoción y escribió sendas cartas pastorales exhortando a los sacerdotes y fieles al culto y la devoción a este misterio cristológico. Tanto en Málaga como después en Sevilla, hizo una fundación, dotándola de su propio peculio para que se solemnizase en ambas catedrales la octava del Corpus hasta enlazar con el siguiente viernes, que es la fiesta litúrgica del Sagrado Corazón ${ }^{11}$. Esta misma espiritualidad adoptó para las religiosas de la Congregación de las Esclavas del Divino Corazón, que fundó ${ }^{12}$ siendo obispo de Coria; expresando con este título, según explica su fundador: "el fin primordial del Instituto: la glorificación del Corazón de Cristo por medio de la entrega total y absoluta a Él, entrega tan completa como la de un esclavo a su señor"13.

Con la misma advocación y espiritualidad, funda en la diócesis malacitana, el 25 de mayo de 1888, la Asociación de Colaboradores del Corazón de Jesús, dirigida a los sacerdotes; la cual tuvo muchos frutos $^{14}$. Lo mismo hizo en Sevilla, cuando el 31 de agosto de 1904 publica los estatutos de la que denomina, Asociación Sacerdotal, cuyas reglas están impregnadas de la misma espiritualidad del Corazón Deífico ${ }^{15}$. En Sevilla, no solo se limitó a encargar la publicación de la encíclica de León XIII sobre la Consagración del Género Humano al Sa-

\footnotetext{
$10 \quad$ AMS F. 66, p. 25.

11 Cf. BOM 6 (1890) 106-107; BOAS 395 (1898) 424.

12 El 26 de julio de 1885, la celebración de la santa Misa en la catedral, presidida por don Marcelo se comunica al pueblo la erección canónica del nuevo Instituto religioso y la finalidad del mismo, teniendo como tarea principal la educación humana y cristiana de las niñas pobres. (Cf. JAVIERRE, J. M., Don Marcelo de Sevilla, Ediciones Sígueme, Salamanca, 1992, p. 323; GONZÁLEZ CHAVES, A. J., Beato Marcelo Spínola. El bien a manos llenas, BAC, Madrid, 2005, pp. 119-122).

13 Estas palabras pronunciadas en la catedral de Coria, quedan recogidas en el art. 2 del capítulo primero de las constituciones vigentes de este Instituto de las Esclavas Concepcionistas del Divino Corazón, en: AMS C C. 5. A.

14 Cf. AMS BOM 6 (1888) 441-463.

15 Cf. AMS BOAS 549 (1904) 189-196.
} 
grado Corazón de Jesús ${ }^{16}$, sino que publicó una exhortación para poner en práctica la encíclica ${ }^{17}$.

Otro hecho que tenemos que conmemorar es, el propósito que tuvo nuestro beato de levantar en Sevilla un grandioso monumento al Sagrado Corazón. Así, en el mes de mayo de 1900 convocó a las damas sevillanas para exponerles el proyecto, y el 31 de diciembre colocó la primera piedra, con toda solemnidad ${ }^{18}$.

Y así, podríamos continuar a lo largo de su amplio magisterio doctrinal, dirigido a sus sacerdotes, religiosas, fieles en general, en el que les exhorta constantemente a poner en práctica la espiritualidad del Sagrado Corazón de Jesús ${ }^{19}$.

\subsection{La visión de Jesús en Spínola, a través del Corazón}

Partiendo de que Jesucristo es la esencia y culmen de la santidad de cualquier vocación cristiana; y puede ser considerado en diversos aspectos, don Marcelo, lo ve siempre desde y a través de su Corazón. Así lo señala en su carta pastoral del 31 de mayo de 1902:

"Hay un Corazón bello cual ninguno, y cual ninguno grande, y puro, y santo como no se vio jamás; Dios lo formó para su Hijo Eterno. Y el Hijo se ha unido a Él y en Él vive, siendo el resorte que lo mueve el Corazón de Jesús. El Corazón de Jesús, que al ponerse en contacto con los de sus hermanos los hombres, se los lleva, los llama, los encadena, los transforma, imprimiendo en ellos su imagen y semejanza $[\ldots]^{\prime \prime 20}$.

Nosotros nos atrevemos a decir, que son dos las razones por las que en nuestro beato, el Corazón de Jesús ocupa esta visión tan central y prominente en su espiritualidad: una primera que llamamos antropológica, y una segunda que denominamos cristológica. A continuación nos disponemos a su interiorización.

16 Cf. AMS LOZANO, M., Encíclica del Señor León XIII Sobre la Consagración del Género Humano al Sagrado Corazón de Jesús, Imprenta de Izquierdo y Cía., Sevilla, 1899, pp. 2-10.

17 Cf. AMS BOAS 413 (1899) 254-262.

18 Cf. MADRE ESPERANZA DEL CORAZÓN DE JESÚS, Vida del Emmo. y Rumo. Sr. Cardenal Arzobispo de Sevilla, don Marcelo Spínola y Maestre, Sevilla, 1924, pp. 405-407.

19 Cf. GRANADO BELLIDO, A., Consagrados a Dios, servidores del mundo, PPC, Madrid, 2005, pp. 318-324.

20 AMS BOAS 492 (1902) 269-270. 


\subsubsection{Visión antropológica}

Con esta denominación, partimos de la función central que ejerce el corazón en cualquier organismo humano: “El corazón es el trono y como el asiento de todos nuestros afectos, los cuales, según la profunda teoría de santo Tomás, pueden resumirse en uno solo: el amor $^{\prime 21}$. Siendo obispo de Málaga escribe en una pastoral, refiriéndose al corazón humano:

“Nada hay más bello bajo el sol que un corazón bueno. Son bellas las flores, es bella la alborada y bella la tarde [...] pero más que todo eso es bello un corazón recto. Porque la flor, la alborada y la tarde, el arroyo, el lago y el río, no tienen vida ni nos responden cuando queremos con ellos hablar" ${ }^{\prime \prime 2}$.

Esta visión antropológica, como la venimos llamando, la encontramos entre tantos escritos; en una carta pastoral con motivo de la fiesta del Corazón de Jesús, en su penúltimo año malacitano escribe:

"Quien dice corazón, dice amor; pues, en verdad, el oficio propio del corazón es amar, como lo es el alumbrar la luz, como es el quemar el fuego, como lo es del entendimiento el razonar y el discurrir. Pero los amores se distinguen unos de otros bajo muchos aspectos; su grado de intensidad, su manera de expresarse, su índole y naturaleza, le dan matices y aun condiciones muy diversas; resultando de aquí que como así nos diferenciamos unos de otros los hombres por la fisonomía, así por los amores se diferencian los corazones humanos $[\ldots]^{\prime \prime 23}$.

Son muchos los textos en los que nuestro protagonista muestra esta visión antropológica en su espiritualidad cristocéntrica, sirva de ejemplo los textos que hemos citado anteriormente.

\subsubsection{Visión cristocéntrica del Divino Corazón}

Si cualquier corazón humano tiene excelencias cuando ama con rectitud, nuestro personaje nos viene a decir, que el Corazón de Jesús, las posee en grado infinito por el rol singular que tiene en la vida de Cristo. Así lo expresa en una de sus pláticas:

\footnotetext{
21 SPÍNOLAY MAESTRE, M., Meditaciones, Editorial La Gaditana, Cádiz, 1928, p. 286.

22 AMS BOAS 354 (1896) 298-299.

23 AMS BOM 6 (1895) 531-532.
} 
“El Corazón de Jesús, como todo corazón es amor; pero siendo la divinidad, elVerbo quien lo habita y quien mueve y como el principio superior de su vida, el amor del Corazón de Jesús ha de ser necesariamente, por su intensidad, el más ardiente de los amores; por su duración, el más constante; por su fuerza, el más firme; por su blandura, el más tierno; y a la vez el más puro, el más noble, el más generoso, el más potente, el más grande de los amores concebibles [...]Y esto bien explica, ya que el Corazón de Cristo es la síntesis de todo lo que piensa, siente, dice y hace Jesús"24.

En una meditación a sacerdotes expone de nuevo esta visión que él tiene del Divino Corazón con una gran clarividencia: "Jesucristo nada habló, nada hizo, nada ejecutó, sin que antes no hubiera tomado parte su Corazón" 25 .

Con motivo de la fiesta del Sagrado Corazón de Jesús, el 19 de mayo de 1887, escribe una carta pastoral en la que intenta convencer a sus sacerdotes y fieles, alcancen esta forma de mirada interior; sirva de ejemplo el siguiente texto:

"Jesucristo es el manantial de donde proviene y adonde va la vida del mundo. Pero hay en Jesucristo mismo un centro del que procede y al que se dirige todo cuanto existe, que es su Corazón. ¿Quién constituyó a Cristo Maestro Universal? [...] Su amor, su compasivo Corazón, abrasado en el deseo de iluminar nuestra ceguera. ¿Quién le movió a presentarse como modelo de santidad? La generosidad de su Corazón, el anhelo de nuestra felicidad, que le apremiaba de día y de noche. ¿Quién le hizo Amigo, Padre, Pastor de los descendientes de Adán? La ternura de su Corazón. ¿Quién lo llevó al calvario? La inefable caridad de su Corazón. Todo, pues, de ese Corazón procede; pero, a la vez, notadlo bien, todo a ese Corazón va"26.

\subsection{El Sagrado Corazón de Jesús, origen y centro de la Iglesia}

Don Marcelo, a este significado de la vida de Jesús, lo elabora en relación con la Iglesia, que la hace corresponder a una proyección fuera de Él, en su obra salvífica en el mundo. En el Archivo de la Casa Museo de Sevilla, se conservan numerosos textos, referentes a este punto que tratamos, entre los que vamos a seleccionar algunos de

\footnotetext{
24 SPÍNOLA Y MAESTRE, M., Pláticas T. I, Imprenta de Franciscco de P. Díaz, Sevilla, 1908, pp. 666-667. Esta misma idea aparece reflejada en uno de los múltiples escritos autobiográficos de tema cristológico, en: cf. AMS F. 5, pp. 17-18.

25 SPÍNOLAY MAESTRE, M., Meditaciones, Editorial La Gaditana, Cádiz, 1928, p. 637. 26 AMS BOM 6 (1887) 91-92.
} 
ellos, que creemos nos darán una claridad sobre este pensamiento de Spínola:

"Del Corazón de Jesús salió una institución que ha sido y es asombro de sus mismos enemigos: la Iglesia Católica [...]"27.

“El amor del Corazón de Jesús subió a las edades primitivas y se difundió entre los primeros cristianos, y de él ha bajado hasta nosotros y bajará a las últimas generaciones ${ }^{\prime \prime 2}$.

“Del Corazón de Jesús saldrá la Iglesia, y de allí sacarán sus apóstoles su celo, allí se fortalecerán sus mártires, allí se formarán los hombres de caridad, las vírgenes que igualarán a los ángeles en pureza, los héroes, en fin, de la santidad. Los justos de todos los tiempos"29.

"La Iglesia es el pensamiento del Corazón de Jesús [...]"30.

"Confesemos que la vida de la Iglesia es vida divina, y lo es porque procede de un manantial divino, el Corazón de Jesús, el cual por eso ha sido llamado el corazón de la Iglesia $[\ldots]^{\prime 31}$.

"[...] Todas las maravillas, para decirlo en una palabra, del orden sobrenatural que vemos con asombro, al Corazón de Jesús deben referirse como a su principio" ${ }^{\prime \prime 2}$.

"La Iglesia, sin embargo, no limita el horizonte de expansión del Corazón de Jesús, sino que es el universo, y, dentro de él, en particular todo lo que constituye la honra y la gloria de la humanidad"33.

\subsection{El Corazón de Jesús, origen de toda santidad}

El lugar central que ocupa el Divino Corazón en el ministerio sacerdotal de Spínola, hace que pueda ponerse en relación con todos los elementos constitutivos que forman el ejercicio del ministerio

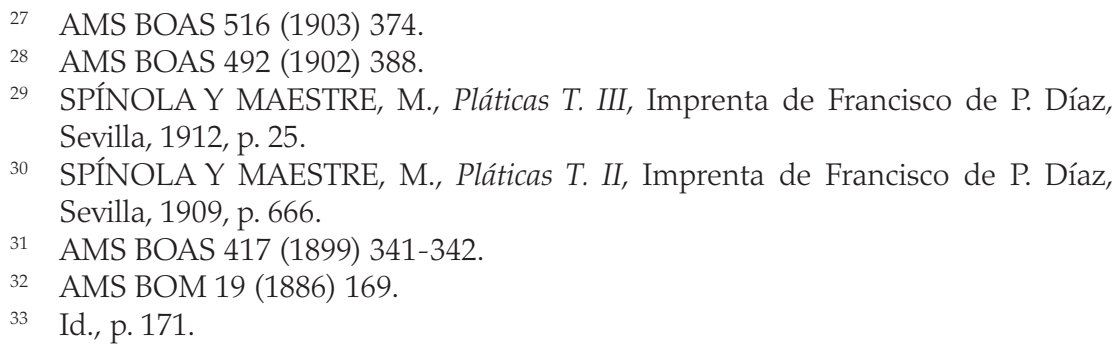

30 SPÍNOLA Y MAESTRE, M., Pláticas T. II, Imprenta de Francisco de P. Díaz, Sevilla, 1909, p. 666.

$31 \quad$ AMS BOAS 417 (1899) 341-342.

32 AMS BOM 19 (1886) 169.

33 Id., p. 171. 
ordenado. Nosotros lo vamos a relacionar ahora con su fin: la santidad; considerada esta en su doble aspecto: en cuanto a la superabundancia de la gracia y en cuanto a la pragmatización concreta en las personas de los santos. En cuanto al primer aspecto, destacamos el siguiente texto dirigido a los sacerdotes en una de sus pláticas:

"El Corazón de Jesús es el centro y origen de toda santidad. Hay muchos santos en la Iglesia, y cada uno brilla con claridad distinta; pero ninguno posee luz propia, incluso la Santísima Virgen, sino que todos reciben la luz del sol de los santos que es el Corazón de Jesús" ${ }^{34}$.

En el segundo aspecto del que tratamos, vamos a citar uno de sus escritos autobiográficos, que lo explicita de forma muy clara:"El gran libro de las almas en el que leen [...] las almas más nobles y elevadas y las más sencillas es, seamos lícito decirlo, el Corazón de Jesús. Este es el texto de los aspirantes a la ciencia de los santos $[\ldots]^{\prime \prime 35}$.

\subsection{La oración, llave maestra del sacerdote}

Para nuestro cardenal, la oración tiene un lugar preponderante, de tal modo que debe convertirse en una ocupación continua del ministerio ordenado, porque es a la vez, expresión de su identidad sacerdotal y el cauce por el que descienden las aguas del manantial de la gracia, que es el Corazón de Jesús. Pues bien, atendiendo a esta premisa, nuestro personaje explica a sus sacerdotes, que esta oración se relaciona con el Divino Corazón de múltiples maneras. A continuación citaremos varios textos suyos, muy clarificadores: "El Corazón de Jesús, entre sus glorias, cuenta la de poder ser apellidado

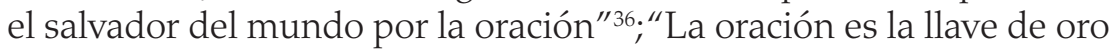
con la cual podremos y debemos abrir los tesoros de Dios, los tesoros del Corazón de Jesús, y sacar de allí cuanto hemos menester [...]"37.

En este contexto del Corazón de Jesús, don Marcelo, usando toda esta serie de metáforas, nos está indicando, que la oración no es solo los ruegos que nos consiguen los dones de Dios, sino también

34 SPÍNOLA Y MAESTRE, M., Pláticas T. II, Imprenta de Francisco de P. Díaz, Sevilla, 1909, p. 648.

AMS F. 18, pp. 17-18.

AMS F. 10, p. 8.

37 SPÍNOLAY MAESTRE, M., Pláticas T. I, Imprenta de Francisco de P. Díaz, Sevilla, 1908, p. 543. 
aquella que nos pone en comunicación y nos revela la interioridad del misterio de Dios: "En momentos dados, Cristo se transfigura, Cristo desabrocha, por así decirlo, su propio pecho y nos muestra su Corazón y las dulzuras infinitas, que en él encierra. Entonces vemos algo de su gloria $[\ldots]^{\prime \prime 38}$.

\subsection{La Eucaristía y la Inmaculada, dones del Corazón de Jesús}

La Eucaristía, su gran amor, don Marcelo la concibe estrechamente relacionada con el Corazón de Jesús. A este respecto, un texto que nos iluminará para comprender esta forma particular que tiene nuestro personaje, de ver a Cristo Eucaristía:

"El sacramento de la Eucaristía es un inmenso mar; un mar sin fondo, un mar que ha brotado en el Corazón de Jesús. [...] Ardía el Corazón de Jesús en un fuego abrasador, un fuego más que volcánico, y el Corazón de Jesús, conmovido, agitado por ese fuego, hundióse, y al mismo tiempo se levantaron en él montañas de misericordias y brotó el mar de la Eucaristía" ${ }^{\prime \prime 3}$.

Podríamos continuar esta antología de textos, que sin duda, prueban el carácter cristocéntrico centrado en el Corazón de Jesús, que tiene nuestro autor, los cuales se multiplican a lo largo de la ingente producción literaria, que sin embargo afirma que:"Todavía no se ha escrito, a pesar de tantos folletos y libros como han salido a la luz acerca del Corazón de Jesús, un tratado completo sobre él. Es que no ha habido quien haya logrado abarcar en su conjunto tanta gloria, tanta grandeza, tantas obras ${ }^{\prime \prime 4}$.

El otro gran amor, sin duda, de nuestro beato es la Virgen, en el misterio de su Inmaculada Concepción; que al igual, encuentra una singular relación con el Corazón de Jesús:

"La primera de las obras del Corazón de Jesús fue María. Sus grandezas y oficios son hechuras del Corazón de Jesús. María y Cristo. Aquella, verdadera madre, le ha dado carne y sangre. Todo lo que es Cristo en cuanto al hombre, es por María. [...] Pero si Cristo debe tanto a María, María debe

38 SPÍNOLA Y MAESTRE, M., Pláticas T. III, Imprenta de Francisco de P. Díaz, Sevilla, 1912, p. 223.

39 SPÍNOLA Y MAESTRE, M., Pláticas T. II, Imprenta de Francisco de P. Díaz, Sevilla, 1909, p. 692.

$40 \quad$ AMS F. 14, p. 27. 
más aun a Cristo: la inmaculada concepción, la maternidad [...] y lo que ella debe a su hijo lo ha tenido por su Corazón, manantial de la sangre redentora y fuente de amor" ${ }^{\prime \prime}$.

"Porción principalísima de la gloria del Corazón de Jesús en el cielo es la Virgen Inmaculada [...] María en la tierra como en el cielo, en la eternidad como en el tiempo, glorificada como viadora, es un monumento gigante; [...] levantado en honra del Corazón de Jesús" ${ }^{42}$.

"La grandeza misma de la Santísima Virgen y hasta la Inmaculada Concepción hechuras son suyas, porque se han formado de materiales por ese mismo Corazón acumulados y con la sangre de Él se amasaron"43.

\subsection{El Corazón de Jesús, más que una devoción}

En este apartado, tenemos que aclarar, que para nuestro beato, el Corazón de Jesús es mucho más que una"devoción", como puede ser la reparación de las ofensas hechas a Jesucristo por nuestros pecados, o el carácter simbólico de este misterio cristológico representado en las sagradas imágenes de Jesús con el Corazón desabierto; sino que es el mismo Jesucristo, en su doble naturaleza, en una misma Persona Divina, que piensa, habla, ama, sufre y muere por puro amor a los hombres. No es por tanto una devoción a una imagen, sino que congrega y penetra en el interior de todas las imágenes sagradas para desabrir en ellas la realidad más profunda de su amor ${ }^{44}$. De esta manera, el sentido reparador y del culto al Corazón de Jesús, nos viene a decir Spínola, que tendrá una dimensión existencial y no solo sentimental ${ }^{45}$.

\subsection{Letanías propias de Spínola al Corazón de Jesús}

Como hemos venido viendo, el Sagrado Corazón, ocupa la centralidad en la espiritualidad de nuestro personaje, que al mismo tiempo abarca su vida en el ejercicio de su ministerio ordenado. Al contener tanta riqueza su vida interior, en relación con este misterio

\footnotetext{
AMS F. 2, p. 4.

AMS BOM 19 (1886) 172.

AMS F. 14, p. 16.

4 Cf. SPÍNOLAY MAESTRE, M., Sermón predicado en la Función de Acción de gracias con motivo del Divino Corazón de Jesús, Sevilla, 1903.

45 Cf. AMS F. 5, pp. 9-12.
} 
cristológico, resulta lógico, que de su pluma se desprenda un torrente literario a través de sus escritos.

Por tanto, en consonancia con las letanías recogidas en los rituales oficiales de la Iglesia, podríamos redactar un conjunto de letanías que contienen la riqueza expresiva, personalizada e incluso original, y que coincidirían con las afirmaciones de las que venimos hablando. Estos serían algunos de los ejemplos de la letanía:

Corazón de Jesús dentro de la vida de Cristo.

Corazón de Jesús, Fuente de donde brotó la Iglesia.

Corazón de Jesús, cuya primera obra fue María.

Corazón de Jesús, Abismo de santidad sin fondo ni riberas.

Corazón de Jesús, Sol de todos los santos.

Corazón de Jesús, Manantial de la vida del mundo.

Corazón de Jesús, bello cual ninguno.

Corazón de Jesús, Tabernáculo de Jerusalén y mansión del Espíritu Santo.

Corazón de Jesús, Peña de Horeb que desprende un raudal inagotable.

Corazón de Jesús, Cúpula que domina el grandioso edificio de la Iglesia.

Corazón de Jesús, Violeta escondida en su pecho.

Corazón de Jesús, lectura de las almas elevadas y sencillas.

Corazón de Jesús, Texto y Libro de los aspirantes a la santidad.

Corazón de Jesús, Mina riquísima de metales preciosos.

Y para concluir este apartado, nada mejor que estas palabras del mismo autor, que pueden servir de síntesis: "No me busque usted en el asunto; búsqueme en el Corazón de Jesús, donde me encontrará. Pues allí estoy. Acaso, más para atormentar a nuestro Señor con mis infidelidades que para consolarle con mi descolorida virtud"46.

\section{La cuestión obrera en la obra del beato Marcelo Spínola}

\subsection{Prolegómenos}

Durante todo el siglo XIX, si hay algún problema importante a tratar, sería la cuestión social y dentro de esta la de los obreros ${ }^{47}$; su situación laboral era bastante precaria, unida a esta situación, que estaban incluidos dentro de las clases más desfavorecidas. Pero esta

\footnotetext{
46 AMS BOM 3 (1887) 46.

47 Cf. ZAGHENI, G., Cursos de historia de la Iglesia IV. La edad contemporánea, S. Pablo, Madrid, 1998, pp. 199-227.
} 
situación se iba agravando, a medida que la industrialización se iba extendiendo, ante lo cual se dieron varias respuestas ${ }^{48}$ : la del movimiento socialista, proponiendo una transformación completa de las estructuras existentes; la del movimiento católico, que de una actitud caritativa y asistencial pasó con prontitud a una actuación social; la de los Estados liberales, que aunque introduciendo gradualmente leyes sociales, tendían al mantenimiento de la situación; la de la Iglesia, que a través de los obispos sacerdotes, incentivó y sostuvo la acción social de las bases, luego con las intervenciones doctrinales del papa León XIII, mediante la encíclica Rerum Novarum del 15 de mayo de $1891^{49}$. Este documento pontificio es la culminación de un itinerario, como veremos en la obra de nuestro personaje, y que constituye el fundamento de las futuras intervenciones de la Iglesia en el campo social.

Las enseñanzas de esta encíclica se pueden resumir en cuatro puntos:

- El Papa defiende la propiedad privada, ya que tiene una función social principal y su fundamento está en la ley natural.

- Obligación del Estado a intervenir y legislar para asegurar los derechos públicos y privados. Este no puede ser neutral y tiene como tarea específica fomentar todo aquello que contribuya al bien común, evitando ponerse al servicio de una parte.

- El principal valor que hay que respetar es la dignidad humana. Hay una serie de derechos que son inviolables para el hombre. Derecho al descanso festivo; al trabajo, según sus fuerzas; a un salario justo...; las leyes deben salvaguardar estos derechos.

- Se condena la lucha de clases y reconoce el derecho de asociación como un derecho natural de los obreros. El Pontífice exhorta a los obreros católicos a constituir organizaciones sindicales propias.

\subsection{Pionero en el episcopado español}

Don Marcelo fue un obispo sensible a los problemas del mundo obrero.Y en este campo, como en otros, su fin último no era otro, que el de hacer presente el mensaje evangélico.

48 Cf. RUIZ SÁNCHEZ, J. L., Política e Iglesia durante la Restauración. La Liga Católica de Sevilla (1901-1923), Diputación Provincial de Sevilla, Sevilla, 1994, pp. 16-21.

49 Nuestro protagonista publica este documento pontificio en AMS BOM 3 (1891) 68-89. Al final de estas páginas, exhorta a todos los párrocos lo den a conocer a sus feligreses. 
Como primera referencia en el pontificado de nuestro personaje, en la cuestión obrera, en una carta pastoral, al poco tiempo de llegar a Málaga como obispo:

"La Iglesia ama al obrero, que no considera injustas las pretensiones por ellos formuladas y que precisamente ella, antes que nadie, despertó en el obrero los sentimientos de su propia dignidad revelándole la naturaleza de su origen, la cumbre de su destino y la augusta misión que en el mundo debe desempeñar [...] pero los obreros, en lugar de apoyarse en sólidos principios de la razón de la fe, invocan el principio socialista en su forma más radical, el anarquismo, principio falso, aun condenado por la fe y la razón [...] El gran medio para poner término al conflicto presente es resucitar el espíritu cristiano ${ }^{\prime \prime 50}$.

Más tarde, encontramos otra carta pastoral relativa a la cuestión obrera, escrita también en Málaga en 1888, en la que entre otras cosas dice: "Los obreros, con quienes nadie contaba, y que parecían dormidos, despiertan, congregándose en numerosas asambleas, discuten con calor, y proclaman en alta y con firmeza los derechos de los que se creen asistidos, aprestándose a reivindicarlos ${ }^{\prime \prime 51}$.

Quizás, lo fundamental del problema de esta cuestión, es que los obreros señalan a la Iglesia como causante del problema que ellos tienen, por una supuesta alianza de esta con la burguesía: "Y al intentarlo, vuelven los ojos irritados contra la Iglesia, pareciéndoles que esta es su enemiga declarada, y aliada íntima de la que en el lenguaje, que nada tiene de castellano, se llama burguesía"52.

Nuestro protagonista siempre defenderá los derechos de la Iglesia, argumentando, que nunca tomó partido con ningún tipo de sociedad, uniendo con ella sus intereses; sino que siempre se ha puesto al lado de los débiles, sean esclavos, niños o mujeres: "Decir, que la Iglesia se ha unido y está identificada con los burgueses y en contra de los obreros, es levantarle torpe calumnia"53.

La Iglesia tampoco, argumentaba nuestro beato, puede ver bien la situación de los obreros, en el momento que son explotados ${ }^{54}$, sin

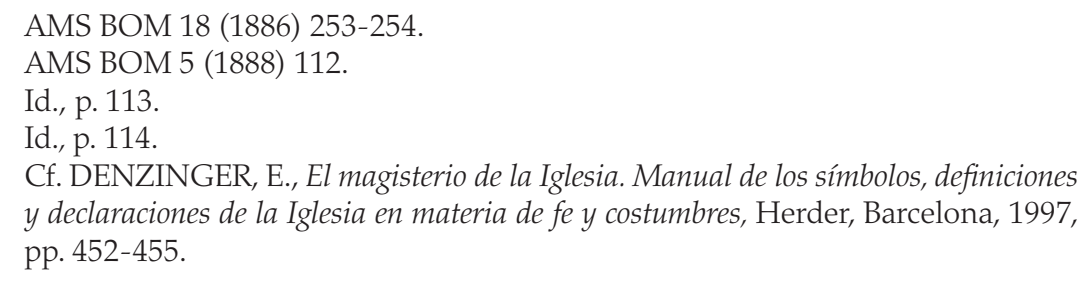
y declaraciones de la Iglesia en materia de fe y costumbres, Herder, Barcelona, 1997, pp. 452-455. 
tener un solo día de descanso para poder celebrar la fe; pero considera, que las justas reivindicaciones no pueden llevarse a cabo de la manera que han escogido tan exacerbada y radical, fundamentadas por principios destructores del mismo hombre, como el anarquismo, y los deshumaniza ${ }^{55}$.

Posteriormente, encontramos de nuevo la cuestión obrera, en una carta pastoral con motivo de la fiesta del Sagrado Corazón de Jesús en $1890^{56}$. Por consiguiente, nos situamos en las vigilias de la encíclica Rerum Novarum de León XIII sobre la problemática social. En dicha pastoral, nuestro personaje, analiza la situación del conflicto, que en general, vive la sociedad, y ve con tristeza lo que está sucediendo en el mundo obrero.

Su gran agudeza e inteligencia le hace anticiparse a lo que después desarrollará la primera encíclica social de la Iglesia, el problema que es la intervención del Estado: "Además, y prescindiendo de la cuestión de principios, pretender los obreros que la mejora de su condición sea el Estado y fruto de la reglamentación legislativa, lo cual es un nuevo error $[\ldots]^{\prime \prime 57}$.

Ante toda esta problemática, Spínola ve como única solución, la de resucitar en la sociedad, el espíritu cristiano. Por eso en la misma pastoral, pide para los obreros el descanso dominical que se ha perdido, y así poder disfrutar de algo tan necesario para el hombre ${ }^{58}$.

Tras la publicación por el santo padre de la encíclica Rerum Novarum en mayo de 1891, encontraremos otra intervención de nuestro personaje, el 13 de junio de ese mismo año, que tras la publicación del texto pontificio, dirige una circular ${ }^{59}$ a sus diocesanos, haciendo un comentario muy claro de todos los principios y respuestas que contiene, sirva de muestra el siguiente texto:"Bien merece calificarse de notable, notabilísimo acaecimiento la publicación [...] en el que S. S. el Papa León XIII aborda con entera franqueza el gran problema de los últimos tiempos [...] y por su relativa trascendencia [...] la cuestión social" ${ }^{\prime 60}$.Y más adelante continúa diciendo:

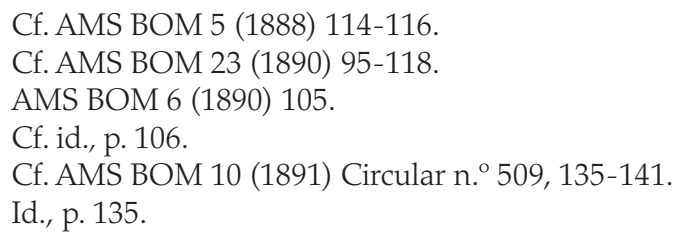


“El Papa emite principios y asienta reglas, que bien meditadas arrojan luz copiosísima, sobre puntos capitales, [...] objetos de disputas [...] el derecho de la propiedad [...] el concepto de igualdad [...] los límites de la acción del Estado [...] el salario justo [...] el descanso [...] el modo de poner término a la crisis que nos perturba [...] la restauración de los principios cristianos $[\ldots]$ y la renovación del orden público $[\ldots]^{\prime \prime 61}$.

Don Marcelo termina este comentario, exhortando a sus sacerdotes, que lean, estudien y saboreen la encíclica, de manera que puedan luego explicar con sencillas palabras a sus feligreses.

\subsection{Sobre la sólida base del mensaje evangélico}

"No nos oponemos a que se estudien los problemas sociales, ni a que se inquiera a la luz de la ciencia el modo de mejorar la condición de los que sufren buscándose medios para impedir, sin atentar a la justicia, la acumulación de la propiedad en unas cuantas solas manos, para procurar la buena y equitativa distribución de las riquezas, para evitar que poseedores del capital vejen u opriman al infeliz obrero, y para conciliar el respeto a la autoridad con libertad del ciudadano. ¿Cómo habríamos de oponernos a esto? Sería no tener amor a los débiles y a los flacos, lo que no se concibe en un cristiano, en un sacerdote, en un obispo, o carecer totalmente de fe en lo que puede y vale el esfuerzo humano"62.

Estas letras anteriores, escritas por nuestro personaje, nos muestran la base de su pensamiento, en su constante preocupación porlos problemas sociales; que no era otra, que el sólido fundamento del mensaje evangélico que conlleva la opción por los más pobres, añadiendo una clara denuncia contra la acumulación de riquezas en manos de unos pocos, más allá de lo que sería justo, a fin de facilitar una equitativa distribución de la riqueza ${ }^{63}$. Es una opción, según se desprende de esta carta pastoral, evitar, sin alterar a la justicia y a la clara referencia a los derechos que debían existir a una y otra parte, era que los poseedores del capital "vejen u opriman al infeliz obrero", para que así se concilie el respeto a la autoridad (por parte de quienes se rebelan contra ella, al no tener nada material porque nada poseían) con la libertad individual común a todo ciudadano por la que nada podía entorpecer el afán de enriquecerse, opción libre de la

$61 \quad$ Id., pp. 136-140.

62 AMS BOM 1 (1892) 46.

63 Cf. AMS BOM 1 (1892) 47-48. 
que carecían en absoluto quienes estaban subyugados por su propia miseria ${ }^{64}$. Pero más allá de los calificativos empleados por nuestro protagonista y del rigor con el que formuló su argumento, Spínola, muestra sobradamente que su pensamiento y su corazón se hallaban siempre en sintonía con el Evangelio.

\subsection{Su firmeza y valentía}

Si nos adentramos en los planteamiento ideológicos del último tercio del siglo XIX, en el que estaban en auge el socialismo y el anarquismo dentro del mundo obrero, no podemos calibrar la importancia y la valentía que encierran todos los escritos pastorales de nuestro beato, referidos a la cuestión social ${ }^{65}$.

Una época ${ }^{66}$ la de nuestro protagonista, en la que todo estaba sometido al imperio de la única ley: que favorecía el enriquecimiento abusivo de los que tenían la riqueza, al tiempo que dejaba desprotegidos completamente a los obreros; una ley que mostraba un modelo ideológico individualista, liberal económico; que dejaba a los trabajadores situados en la marginalidad e indigencia, que solo podían esperar de las instituciones benéficas y de caridad, en su mayoría impulsadas por la Iglesia ${ }^{67}$. Unos planteamientos, que en palabras de nuestro personaje, rendían culto"a la teoría hegeliana de la omnipotencia del Estado, que hace de este el árbitro de todas las relaciones, y el solo juez llamado a dirimir con sus sentencias la presente formidable querella" 68 .

\subsection{Una respuesta doctrinal distinta a las ideologías existentes}

En este contexto histórico tan complejo, se sitúa la respuesta doctrinal que dio el beato Marcelo Spínola, siempre en consonancia con el santo padre. Una respuesta ${ }^{69}$, la de nuestro protagonista, muy valien-

\footnotetext{
64 Cf. id., pp. 48-50.

65 Cf. RUIZ SÁNCHEZ, J. L., La confrontación católico-laicista en Andalucía durante la crisis entreguerras, Universidad de Sevilla, Sevilla, 2012, pp. 17-21.

66 Cf. RUIZ SÁNCHEZ, J. L., La sociedad del XIX. Historia de la humanidad, Arianza, Madrid, 2001, pp. 72-98.

67 Cf. AMS BOM 2 (1892) 29-53.

68 AMS BOM 2 (1892) 54.

69 AMS BOM 10 (1891) Circular n. ${ }^{\circ}$ 509, 136.
} 
te ante posicionamientos radicalmente contrapuestos. Una situación difícil que alarmaba y preocupaba, y ante la que nuestro autor, marcaba una oportuna distancia y fuerte; ni se aliaba para santificar la ley del mercado, ni rendía culto a la omnipotencia del Estado; porque ninguno de ellos respondía a planteamientos cristianos:

"Una cosa llama desde luego la atención, y es que turba la paz pública declarando la guerra a la propiedad, al capital y a los poderes legítimos, ni los que son objeto de sus querellas, el rico que del pobre se olvida, el capitalista que no tiene miramientos con el operario de su taller o de su fábrica, el gobernante, hiere, lastima, molesta y esquilma a los gobernados, son fieles observadores de la Cuaresma. Seguid sus pasos y veréis como, ni ayudan ni asisten a la Iglesia, a no ser que a ella los lleve el deseo de oír a célebre orador o de escuchar melodías no vulgares, ni oran, ni reciben los sacramentos. Este hecho por sí solo habla muy alto"70.

Para Spínola, la solución de este conflicto pasaba por buscar una respuesta no desde las ideologías, sino trazando conductas morales, que restauren el orden cristiano de los Estados. Es verdad, que a la hora de señalar responsabilidades, tendía a distribuir culpas; pero tenía un especial miramiento hacia los más perjudicados en este conflicto: los obreros. Así lo defendía con toda rotundidad:

"Es un hecho innegable, que no siempre se ve bien tratado el obrero por los que dueños del capital lo utilizan para la producción y aumento de la riqueza; consintiendo el abuso en dos puntos principales: primero, en la entidad del salario, que suele no guardar proporción con las necesidades del obrero, [...] segundo, el exceso del esfuerzo que se le exige, el cual lo enerva, lo debilita y lo envejece o pone inútil antes de sazón $[\ldots]^{\prime \prime 71}$.

Más adelante nos dirá, que las razones de este proceder se derivan de la codicia, del egoísmo, del individualismo y materialismo imperante, en definitiva: al alejamiento de Dios y en su lugar, al culto idolátrico de la riqueza y el poder ${ }^{72}$.

En una carta pastoral con motivo de la Cuaresma, nos dirá nuestro beato, que para poner fin a estas luchas de clases tan radicalizadas, solo habría un camino, el que marca la Iglesia; buscando la armonía entre los que poseen la riqueza, los capitalistas, y quienes

\footnotetext{
AMS BOM 3 (1891) 46-47.

AMS BOM 5 (1892) 107.

72 Cf. AMS BOM 5 (1892) 107-108.
} 
solo eran dueños de su esfuerzo manual, los obreros o proletarios; favoreciendo el diálogo, reuniones y convivencias en determinados organismos $^{73}$. Esta fue su línea de respuesta al conflicto social; una aportación, sin duda, no desde la caridad sino desde la justicia social.

\subsection{Los círculos católicos de obreros}

La guerra entre capital y trabajo, buscó entonces como remedio los "círculos católicos de obreros"74. En su seno se fueron desarrollando variados organismos (cooperativas, bolsas de trabajo, escuelas de adultos, economatos, cajas de ahorros, entre otros) que servían, en la medida de lo posible, para lograr con justicia la armonía entre las clases sociales enfrentadas ${ }^{75}$.

En España, con la llegada al trono de Alfonso XII, posibilitaron su expansión por todo el reino ${ }^{76}$.

Nos consta que nuestro protagonista, era un entusiasta de estas obras del PadreVicente ${ }^{77}$. Ya en 1887 consiguió abrir uno de estos círculos en Málaga ${ }^{78}$. Años más tarde, en la misma sede malacitana, proponía la necesidad de implantar estos círculos como recurso que podía dar mucho fruto ${ }^{79}$.

Recién instalado en la sede hispalense, escribió una circular muy extensa en la que denunciaba a los enemigos de Cristo y de su Iglesia, los cuales, utilizaban a los obreros y no precisamente para mejorar su situación de vida:

"[...] la clase obrera es hoy objetivo, en que tienen puesta la mirada los enemigos de Cristo y de su Iglesia, quienes utilizan las desdichas de los

73 Cf. AMS BOM 2 (1892) 46-47.

74 Cf. SANZ DE DIEGO, R. M., "El Padre Vicente: Años de catolicismo social en España (1866-1912)": Revista Miscelánea de Comillas 38 (1980) pp. 267-296; MARTÍNEZ ESTEBAN, A., Aceptar el poder constituido: los católicos españoles y la Santa Sede en la Restauración (1890-1914), Publicaciones de la Facultad de Teología"San Dámaso", Madrid, 2006, pp. 95-104.

75 Cf. GARCÍA NIETO, J. N., El sindicalismo cristiano en España, Universidad de Deusto, Bilbao, 1960, pp. 287-296.

76 Cf. ANDRÉS-GALLEGO, J., "Los círculos obreros (1864-1887)": Hispania Sacra 29 (1976) pp. 259-304.

77 Cf. ANDRÉS-GALlEGO, J., Pensamiento y acción social de la Iglesia en España, Espasa Calpe, Madrid, 1984, pp. 329-345.

78 Cf. AMS BOM 4 (1887) 71-73.

79 Cf. AMS BOM 5 (1893) 421. 
infelices miembros de esa clase y sus aspiraciones, explotan su ignorancia y sus apetitos, no para buscar el mejoramiento de su suerte [...] sino sublevándolos contra personas, cosas e instituciones, y para ello los engañan, atribuyendo la culpa de sus infortunios a quienes jamás fue su causa, sino antes los deplora vivamente, y anhela su término" ${ }^{\prime 80}$.

Ante esta realidad social, el obrero se veía asediado de tentaciones: al escuchar las injusticias del capitalista en el taller; o cuando faltaba lo necesario para vivir; cuando escuchaban y leían en la prensa el odio de las clases sociales. Pero lo peor de todo, era que no había quien les ilustrase; guías y maestros que le hicieran ver la mentira de los argumentos que escuchaban por doquier:"Por eso es desgraciado el obrero, y no puede menos que excitar la conmiseración y el interés del obispo, que lo ama como un padre a sus hijos [...]"81. Más adelante, aludía a la necesidad de crear estos centros de integración para los trabajadores:

"[...] la suerte de los obreros no puede sernos indiferente, y veríamos con indecible complacencia a los buenos católicos [...] trabajar con ardor en esta empresa, y crear círculos y centros en una y otra forma, donde el obrero hallara lo que ha de menester, defensa contra sus seducciones y asechanzas de todo linaje, a que se le somete $[\ldots]^{\prime \prime 82}$.

A pesar de las enormes dificultades que suponía el establecimiento de estos centros ${ }^{83}$; en 1892 se funda un centro en Dos Hermanas y otro en Jerez de la Frontera ${ }^{84}$, entonces de la archidiócesis. Sabemos que en 1896 se había fundado un centro católico instructivo para obreros de Carmona; también el 12 de febrero de 1898 quedó inaugurado el Círculo Católico de obreros de San Francisco Javier, en la sevillana calle de San Benito de Calatrava, vinculado a la obra salesiana; en 1899 las congregaciones marianas de los jesuitas, abrió otro centro de esta misma naturaleza; en 1903 se fundaron círculos en Écija, Morón de la Frontera, Montellano, Lebrija, La Puebla de Cazalla; al año siguiente se instaló en Mairena del Alcor y en Gerena, Huelva y el de Sevilla en la calle Rivero. Aunque fueron resultados

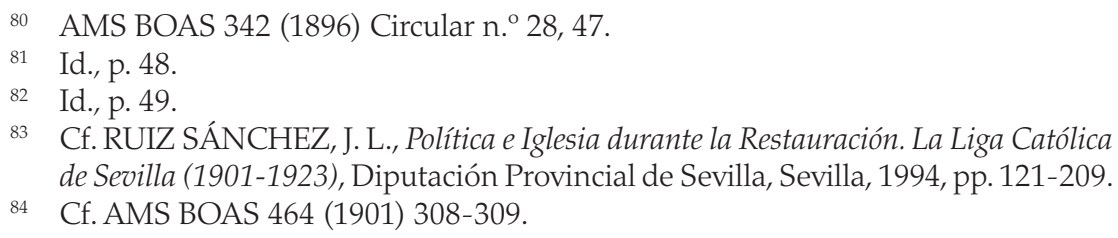


exiguos, sirvieron de base para el desarrollo extraordinario que tuvieron esas instituciones y otras más novedosas tras la muerte de nuestro beato, ya propiamente sindicatos católicos agrarios, en casi un centenar de municipios de la jurisdicción diocesana ${ }^{85}$.

\subsection{Un referente para el mundo obrero}

En su vida, a lo largo de los años, adoptó distintas medidas preventivas para evitar o al menos paliar alguno de sus males. Al margen de las suyas propias, anteriormente mencionadas de su puño y letra, se valió también de instituciones y organismos a los que promocionó, por considerarlos útiles. A algunos de ellos nos vamos a referir a continuación. Nuestro personaje siempre tuvo gran estima a la labor que desarrollaban los salesianos. Siendo obispo auxiliar de Sevilla, favoreció la instalación de la primera casa de los hijos de D. Bosco en España, concretamente, en Utrera ${ }^{86}$. Tanto admiraba su obra y sus virtudes, que escribe la primera biografía, todavía en vida ${ }^{87}$. Siendo obispo de Málaga, hizo grandes esfuerzos, hasta que consiguió que se instalaran en su diócesis en 1895, para que acogieran a los niños desamparados y faltos de toda clase de educación ${ }^{88}$.

La enseñanza de un oficio a los niños y jóvenes, con el que poderse ganar la vida, era el mejor medio para evitar problemas en el mundo obrero, y eso solo lo hacían perfectamente los salesianos. Esta congregación pionera en la Iglesia, estaba planteando la formación profesional, cuando esta ni existía ni era un objetivo de la educación del Estado. De esta manera, se sacaba de la marginalidad a una generación abocada sin ningún futuro profesional. Por esto, nada más llegar a Sevilla, nuestro personaje ${ }^{89}$, hizo la primera visita a los salesianos instalados en la Trinidad, entonces un barrio marginal. Así la prensa del momento recogía la trascendencia de la visita:

85 Cf. RUIZ SÁNCHEZ, J. L., Política e Iglesia durante la Restauración. La Liga Católica de Sevilla (1901-1923), Diputación Provincial de Sevilla, Sevilla, 1994, pp. 324-368.

86 Cf. AMS Carta de san Juan Bosco dirigida a don Marcelo del 13 de mayo de 1885: en AMS C C. 1. 1. B.

87 Cf. SPÍNOLAY MAESTRE, M., Don Bosco y su obra, Editorial CCS, Madrid, 2012.

88 Cf. AMS BOM 7 (1895) 568-570.

89 Cf. BORREGO, J., "Un gran cardenal hispalense con la familia salesiana, visto en su correspondencia epistolar a los salesianos": Ricerche storiche salesiane 27/II (1995) pp. 321-392. 
"La educación completa del obrero cristiano, la enseñanza religiosa y técnica de las clases más pobres y desvalidas [...] reviste en los tiempos socialistas que corremos una importancia tan excepcional, que nadie ha podido ponerla en duda [...] Más de mil adolescentes pobres acuden a sus escuelas y talleres y otros cien internos reciben además alimento y cama por milagro de la caridad $[\ldots]^{\prime \prime 90}$.

La admiración de nuestro autor hacia la obra de D. Bosco fue una constante a lo largo de su vida:

“[...] el amor, decimos que D. Bosco tuvo al obrero, está presente en su obra de los talleres salesianos. Allí no se especula; no se utilizan los brazos del adolescente y del joven a fin de hacerlos producir y así crear una respetable riqueza [...] solo se procura una cosa, formar obreros cristianos, católicos [...] preservar al individuo de la corrupción y el vicio, que son una ruina, y regenerar a la clase obrera $[\ldots]^{\prime \prime 1}$.

También en 1902 se puso en marcha con carácter diocesano el "Apostolado de señoras para el mejoramiento moral y social de la clase obrera". Su fin era llevar la instrucción a los obreros y obreras. Solo en Sevilla tenían acogidos a más de tres mil en un total de 26 poblaciones en las que estaban instaladas, educando a 24.705 personas de ambos sexos ${ }^{92}$.

Otro gran problema, era cuando los obreros con sus hijos pequeños tenían largas jornadas de trabajo y no podían ni siquiera darles de comer, y sin abrigo de otros muchos peligros. Fue entonces, a comienzos de 1901, cuando quedó constituida en la capilla del palacio arzobispal el Patronato de la Niñez ${ }^{93}$. Con este fin, un grupo muy numeroso de señoras caritativas hacían lo que hoy en día se llama, guarderías infantiles.

Esta prevención del mal, siempre fue una constante en su vida, mostrando una comprensión paternal hacia los más pobres y necesitados, incluso en difíciles circunstancias ${ }^{94}$.

90 La noticia de la prensa fue reproducida en el boletín diocesano en la sección de noticias. (Cf. AMS BOAS 339 [1896] 217-220).

$91 \quad$ AMS BOAS 479 (1901) 277-278.

92 Así lo recoge el boletín oficial de la archidiócesis de 25 de octubre. (Cf. AMS BOAS 477 [1901] 277-278).

93 Con el título"Una obra de caridad más en Sevilla" se publica en: Cf. AMS BOAS 457 (1901) 173-174.

94 A comienzos de 1901, reverdeció el anticlericalismo en todo el país, también en la ciudad de Sevilla; pero de una manera más radical e incisiva, durante el mes de 
Don Marcelo, mostró siempre una particular sensibilidad con todo lo relacionado con la cuestión social del momento. Intervino en ese mecanismo complejo que regula las relaciones entre capital y trabajo, aportando su criterio, que estaba en consonancia con el magisterio de la Iglesia, poniendo en marcha en sus diversos pontificados, todos los mecanismos y resortes a su alcance.

\section{EN LA TRIBUNA DEL SENADO}

\subsection{Prolegómenos}

La política fue otro de los ámbitos en los que don Marcelo ejerció con inteligencia y decisión su oficio de pastor.Y lo hizo en la Cámara Alta ${ }^{95}$, y como Senador del Reino. En la España decimonónica, cada región contaba con un representante eclesiástico. Granada, como provincia eclesiástica, a la que pertenecía la diócesis de Málaga, le eligió para ocupar el cargo de Senador el 15 de febrero de 189196; dos años más tarde se repitió el encargo que desempeñó ininterrumpidamente hasta el final de su vida, ya que al llegar a Sevilla, lo obtuvo por derecho propio. Siempre y en todo momento lo hizo con un gran sentido de la responsabilidad; de servicio a la Iglesia y a la patria ${ }^{97}$.

octubre, en medio de la campaña electoral; cometiéndose atentados contra personas y cosas religiosas. Nuestro personaje, en un boletín oficial se dirige a los obreros, con firmeza y a la vez con sentido paternal. (Cf. AMS BOAS 477 [1901] 265-279).

95 La Constitución de 1876, disponía que en el Senado pudieran tomar asiento los obispos, de entre los elegidos por las corporaciones del Estado, como representantes de las provincias eclesiásticas. Por el contrario, el Patriarca de las Indias y los arzobispos eran senadores por derecho propio. (Cf. RUIZ SÁNCHEZ, J. L., "Vida y obra de Marcelo Spínola y Maestre (1835-1906)", en: J. M. MÁRQUEZ DE LA PLATA CUEVAS - M. MARTÍN RIEGO - J. L. RUIZ SÁNCHEZ, Marcelo Spinola. Estudios en un Centenario (1906-2006), Fundación Universitaria San Pablo CEU, Sevilla, 2006, pp. 246-247).

96 Su nombramiento y elección fue publicado en: (AMS BOM 1 [1891] 29-31); también se encuentra copia de la documentación original de su nombramiento en AMS C C. F. 5. 7.

97 Cf. MADRE ESPERANZA DEL CORAZÓN DE JESÚS, Vida del Emmo. y Romo., Sevilla, 1924, p. 331; JAVIERRE, J. M., Don Marcelo de Sevilla, Ediciones Sígueme, Salamanca, 1992, pp. 392-398; DE SOBRINO, El Venerable Spinola, BAC, Madrid, 1984, p. 71; GONZÁLEZ CHAVES, Beato Marcelo Spinola. El bien a manos llenas, BAC, Madrid, 2006, pp. 188-193. 


\subsection{Sus intervenciones en la Cámara Alta}

Atendiendo a una $\mathrm{u}$ otra circunstancia, tuvo la oportunidad de intervenir desde la tribuna de oradores en distintas ocasiones, al igual que sus hermanos del episcopado, y lo hizo en ocasiones puntuales y de manera precisa sobre cuestiones que afectaban a la Iglesia y su misión ${ }^{98}$.

El lunes 8 de junio de 1891 se estrenó en el Senado. La cuestión que le tocó defender era, la ley que afectaba al descanso dominical. El problema se había centrado en si dicho descanso era obligatorio para aquellos que no fuesen católicos. Esta responsabilidad contraída le apesadumbraba, como lo expresaba en una carta a su hermana Rosario $^{99}$. Aún así, intervino en tres momentos del debate, argumentando siempre por los fueros de la Constitución y sobre todo en la aplicación del art. 11. A continuación vamos a transcribir algunos de los párrafos más importantes desde la tribuna de oradores:

“[...] me atrevo a combatir el artículo $2^{\circ}$ del proyecto, o mejor dicho, más que a combatir, a pedir que se reforme en el sentido que se anulen por completo los pactos relativos a la violación del trabajo dominical o de los festivos, sean cualesquiera los que los formulen, católicos o no católicos" ${ }^{\prime 100}$.

Y siguiendo el discurso argumenta:

“El artículo 11 de la Constitución, que vosotros habéis estudiado perfectamente, dice que la religión católica apostólica romana, es la religión del Estado; de donde se refiere que el Estado en España es católico, y tiene por tanto, los derechos, juntamente con los deberes de un Estado Católico [...] al Excmo. Sr. Ministro de Gracia y Justicia cuando nos habla de la protección del Estado para con la Iglesia [...] no debe ser de palabra, sino de obra [...] no debe ser imaginativa, sino una realidad. Pues bien, si esto es cierto [...] será digno de él prestar sanción a puestos, a convenios, a contratos que terminantemente se oponen a los preceptos más sagrados [...] ¿Qué protección sería esta, Señores?"101.

98 Cf. Cf. DENZINGER, E., El magisterio de la Iglesia. Manual de los símbolos, definiciones y declaraciones de la Iglesia en materia de fe y costumbres, Herder, Barcelona, 1997, pp. 428-429.

99 Cf. AMS F. 85, p. 20.

100 Id.

101 Id., pp. 1014-1015. 
Más adelante continuó el discurso argumentando con gran elocuencia:"Es verdad que entre nosotros (y el mismo art. 11 de la Constitución lo dice) tolerancia religiosa; pero la tolerancia religiosa no es la libertad de cultos; hay entre ambos una diferencia inmensa $[. . .]^{\prime \prime 102}$. Y termina su intervención apelando:

"Y termino rogándoles a los Señores Senadores, que puesta la mano en el pecho, levantando la mirada a lo alto, y considerando que España entera aguarda su fallo, lo pronuncien, y lo pronuncien en el sentido que he indicado. Los presentes y los venideros se lo agradecerán, y la Iglesia y la Patria les bendecirán. He dicho"103.

Ese mismo día por la noche, escribe como de costumbre, una carta a su hermana Rosario, en la que le dice:

“[...] yo te hablo la verdad, te digo que mi discurso nada valió, pero causó honda sensación, hasta el punto de dar motivo a que la discusión se suspendiera antes de tiempo, a fin de que consultado Cánovas, se viese si se modificaba o no el artículo por mí combatido $[\ldots]^{\prime \prime 104}$.

Posteriormente, el martes día 9 interviene de nuevo en relación a la misma cuestión, de la que entresacamos el final de su intervención:

"Es pues cierto, que dentro de la Constitución cabe la prohibición del trabajo en el día festivo a los católicos y a los no católicos, [...] Por lo demás, el Gobierno sabe perfectamente cuales son los sentimientos que animan a los obispos. No queremos luchas, no queremos guerras: queremos la concordia, aspiramos a la perfecta armonía de la Iglesia y el Estado. Si se nos da, pues lo exigimos, no para nosotros, sino para honra de Dios y bien de las almas, inclinaremos nuestra cabeza [...] con tal de que los intereses sagrados que nos están encomendados queden a salvo [...] He dicho"105.

Al día siguiente le escribe a su hermana Rosario diciéndole:

102 Id., p. 1015.

103 Id.

104 AMS F. 85, p. 26.

105 AMS (Diario de sesiones de Cortes. Senado n. ${ }^{\circ}$ 64, siendo presidente el Excmo. Sr. D. Arsenio Martínez de Campos, 1029) en: AMS C C. F. 5. 7. 
"[...] lo que te puedo asegurar, es que mi triunfo de nuevo ayer, tiene mucho más de aparente que de real, y que el proyecto, a pesar de mis esfuerzos, no mejorará gran cosa"106.

En 1894 volvió a intervenir en la tribuna de oradores. En esta ocasión fueron temas relacionados con la enseñanza. En el mes de mayo lo hizo sobre la libertad de cátedra; si por ello se entendía que el profesor podía enseñar malas doctrinas y así, llevar a las inteligencias y conciencias por el camino del mal, la libertad de cátedra, no solo era mala y perniciosa, sino un atentado contra el derecho de los padres ${ }^{107}$.

$Y$ a finales de ese mismo año, concretamente los días 4, 5 y 6 de diciembre, abordó un tema importante: la enseñanza de la religión en los centros públicos de enseñanza secundaria. Durante los primeros años de la Restauración los planes de estudio (que eran los del anterior momento político) excluían la enseñanza de la religión de los centros. En los planes de 1894, tampoco figuraba, lo que dio lugar a un debate en el Senado, en el que intervino de una forma destacada. Al final se llegó a una transacción entre los que querían incluir la asignatura con carácter obligatorio y aquellos que se oponían, consistente en su inclusión en el plan de enseñanza secundaria, pero sin el carácter obligatorio ${ }^{108}$.

Don Marcelo no volverá a intervenir en la tribuna de oradores, hasta el 30 de octubre de 1901. El asunto era, sobre la reciente venta del Seminario de Sevilla; del que la prensa anticlerical y ciertos círculos de la ciudad, hacían eco de críticas y murmuraciones contra Spínola por dicha venta, al Ayuntamiento hispalense. En la sesión de la tarde el senador Palomo y Ruiz quiso echarle un guante con el fin de zanjar la cuestión mediante su intervención ${ }^{109}$.

Nuestro personaje tras pedir la palabra al presidente, el Excmo. Sr. D. Eugenio Montero Ríos, daba una serie de explicaciones que

106 AMS F. 85, p. 28.

107 Dicha intervención se produjo el día 9 de mayo de 1894, y quedó reflejada en el Diario de sesiones del Senado correspondiente a esa fecha. (Cf. AMS C C. F. 5. 7.).

108 Las intervenciones que tuvieron lugar los días 4, 5 y 6 de diciembre de 1894 quedaron reflejadas en el Diario de sesiones del Senado correspondientes a esas fechas. (Cf. AMS C C. F. 5. 7.).

109 Cf. AMS (Diario de sesiones de Cortes. Senado n. ${ }^{\circ} 64$ de 30 de octubre de 1901, 2), en: AMS C C. F. 5. 7. 
argumenta dicho proceder. Con su intervención ${ }^{110}$, serena y concisa, quedó pública y oficialmente aclarado el tema, y con ello se puso fin a las críticas y murmuraciones sufridas, en los periódicos y "mentideros públicos".

La tercera vez que interviene en la tribuna de oradores, fue el día 4 de noviembre del mismo año, el tema era la vinculación con América, con ocasión del Congreso Hispano-americano celebrado en México en 1900. En ella, Spínola hace un gran discurso enalteciendo el patriotismo y la evangelización de aquellas tierras ${ }^{111}$.

El día 8 de noviembre de 1901, volvió a intervenir, el tema era ahora de suma importancia: defender la obligatoriedad de la religión de los alumnos de los institutos, simplemente a los que eran católicos; siendo su interlocutor el conde de Romanones, a la sazón ministro de Instrucción Pública. Su proposición, fue argumentada con un repaso de la historia (desde Constantino hasta san Fernando Rey) de la formación de la personalidad, y sobre todo, una vez más, con la Constitución en la mano $^{112}$. Pero la base de su argumento iba mucho más allá:

"El Estado no ha recibido de nadie el encargo de enseñar; tiene autoridad y poder para regular las relaciones entre asociados, para proteger y amparar los derechos legítimos, pero no posee la ciencia ni la potencia de definir el error y la verdad; [...] No, no es conforme a la misión del Estado el que sea docente [...] Desde el momento en que el Estado se erige en maestro, nadie sabrá sino lo que él quiere que sepa, nadie conocerá sino lo que él le enseñe, y será por tanto dueño y señor de los asociados"113.

Recordaba al respecto lo que decía Napoleón:“Mi objeto al buscar el cuerpo docente ha sido tener un medio de dirigir las opciones morales y políticas"114.

A medida que arrancaba el discurso, se mostraba más rotundo y contundente frente a su interlocutor:

110 Cf. AMS (Diario de sesiones de Cortes. Senado n. 48 de 30 de octubre de 1901, 4) en: AMS C C. F. 5. 7.

111 Cf.AMS (Diario de sesiones de Cortes. Senado n. ${ }^{\circ} 21$ de 4 de noviembre de 1901, 179-180) en: AMS C C. F. 5. 7.

112 Este fragmento, se encuentra reflejado en el Diario de sesiones del Senado, correspondiente al día 8 de noviembre de 1901, siendo presidente el Excmo. Sr. D. Eugenio Montes Ríos, en: cf. AMS C C. F. 5.7.

113 AMS C C. F. 5.7.

114 Id. 
"Así pues, el Estado docente es el Estado déspota, el Estado tirano, amo, a la vez que de los entendimientos y voluntades [...] se convierte en elemento de retroceso que impide el adelanto de las Ciencias y de las Letras [...] yo pido a los señores senadores, y espero lo concederán, que se establezca como obligación la asignatura de religión en los institutos y centros docentes, y juntamente a la vez se otorgue amplia libertad de enseñanza en nuestra Patria"115.

Las respuestas de Romanones fueron escurridizas, recorriendo los canales de la demagogia ${ }^{116}$.

Para concluir este apartado, relativo a sus intervenciones en la tribuna del Senado, tenemos que decir, que don Marcelo tuvo una impresión bastante negativa de la vida parlamentaria en la Cámara Alta. En una carta que escribe a su hermana Rosario dice lo siguiente:

"Mi vida en estos días, ha quedado reducida a hacer algunas visitas y a asistir al Senado, cuyas sesiones duran cuatro horas, desde las 3 a las 7 de la tarde [...] son cansadísimas. Aquello no tiene ni apariencia de cosa seria; y disparates se dicen en abundancia"117.

Sus críticas son igualmente para el papel de los prelados en la Cámara, ya que no existía coordinación entre ellos. Y más allá, le disgustaba el ambiente de Madrid y todo el aparato burocrático. En una carta posterior, volvía a decirle a su hermana Rosario:

"[...] con todo esto comprenderás que no puedo hallarme contento, ni mucho menos. Yo, que no sé más que estar en mi rincón, con mis papeles, mis libros y mi oratorio [...] ¿cómo he de avenirme a Madrid? En fin, todavía no desespero de sacudir esta carga que no sé desempeñar"118.

Más allá de todo lo que expresa sobre sí mismo, en el desempeño del cargo de Senador, son muchos los testimonios sobre Spínola, que contrastan su valía y su gran capacidad para estas tareas, no solo entre los prelados, encabezados por el Nuncio, sino también,

115 Id.

116 En el Diario de sesiones del Senado correspondiente al día 8 de noviembre de 1901, quedan reflejadas estas palabras del Sr. Ministro de Instrucción Pública, en: cf. AMS C C. F. 5. 7.

117 AMS F. 88, p. 20.

118 AMS F. 81, p. 47. Otro comentario de cariz negativo sobre el Congreso de los Diputados, en la que lo compara con un lavadero, se lo hace a su hermana Rosario en una carta que le dirige desde Madrid, en: AMS F. 81, p. 37. 
por determinados políticos que admiraban su claridad, franqueza y elocuencia, sin rodeos, con los que defendía sus argumentos ${ }^{119}$.

\section{LA ORGANIZACIÓN DE LA PRENSA Y LA PROPAGANDA CATÓLICA. LA FUNDACIÓN DEL DIARIO CATÓLICO: EL CORREO DE ANDALUCÍA}

\subsection{Prolegómenos}

Cuando en el siglo XVIII se produjo el triunfo revolucionario de las libertades, los textos impresos jugaron un papel destacado. La prensa periódica fue el principal conductor de propaganda liberal, defensores de la secularización y contrapuestos a la Iglesia ${ }^{120}$.

Con la llegada de la Revolución de 1868, la Iglesia Católica se dio cuenta de que los púlpitos tradicionales, no eran suficientemente útiles y eficaces para combatir las ideas del liberalismo y su propaganda, que estaban socavando los principios morales del cristianismo; hacía falta disponer de tribunas sólidas, desde donde defender los planteamientos y principios de la Iglesia ${ }^{121}$.

Don Marcelo, desde fecha temprana, hizo ver a sus colaboradores, la importancia que iba adquiriendo la prensa. A su llegada a Málaga, en su primera exhortación dirigida al clero les ponía sobre aviso de la peligrosidad de las numerosas y variadas publicaciones (libros, revistas, folletos, periódicos) que tenían un abundante público y una de cuyos objetivos habituales era denigrar al clero ${ }^{122}$.

Al llegar a Sevilla, diez años más tarde, encontró el mismo panorama que hemos apuntado en letras anteriores. Al verse atacado por la prensa en el reparto de hojas anticlericales, abordó el tema:

"Verse holladas con harta frecuencia todas las leyes: las leyes de la gramática, olvidándose las más elementales de la síntesis; las leyes de la buena

119 Todos estos comentarios, enalteciendo su brillantez y elocuencia parlamentaria, los encontramos en las cartas privadas dirigidas a él, en: cf. AMS C C. 1. 4.

120 Cf. RUIZ SÁNCHEZ, J. L., Prensa y propaganda Católica (1832-1965), Editorial Universidad de Sevilla, Sevilla, 2002, pp. 13-34.

121 Cf. HIBBS-LISSORGUEZ, S., "Iglesia, prensa y sociedad en España (1868-1904)”, en: E. LA PARRA LÓPEZ (dir.), Ensayo e investigación, Diputación Provincial de Alicante - Instituto Alicantino de Cultura Juan Gil-Albert, Alicante, 1995, pp. 359-365, 403-425.

122 Cf. AMS BOM 19 (1886) 167-168. 
literatura, distinguiéndose muy a menudo tales escritos por su pésimo gusto; las leyes del decoro y aún lo que es más doloroso, las de la moral y la Religión $[\ldots]^{\prime \prime 123}$.

Para nuestro autor, este tipo de prensa y propaganda, resultaban muy negativos para las creencias, ocasionando muchos males, y muchos de ellos irreparables. Como hemos visto en las letras anteriores, la prensa liberal batallaba sin piedad contra la Iglesia. Desde distintas instancias, se reclamaba la necesidad de contar con una prensa propia, que fuese en verdad católica, sumisa a las directrices y doctrinas del episcopado español; diferente a la que ya existía, la cual utilizada por los carlistas e integristas, reacios a las disposiciones pontificias y al episcopado español, siempre atrincheradas en disputas estériles y polémicas intestinas, que no aunaba esfuerzos en pro de una misma causa: la Iglesia ${ }^{124}$.

Lo que más se echaba en falta, era, el que hubiera un diario de gran tirada y circulación, y no la multiplicidad de publicaciones pequeñas, en su mayoría de contenidos diferentes.

\subsection{La implicación de Spínola}

Su implicación en estos asuntos fue creciente, es decir: de reflejar y aplaudir lo que se hacía en otros lugares, a la puesta en marcha de determinados mecanismos diocesanos en los que personalmente se implicaba, bien como promotor o como colaborador entusiasta. Nuestro personaje, consideraba fundamental, para la recristianización de España, contar con medios de comunicación y de propaganda propios $^{125}$.

\subsubsection{Desde sus letras}

Ya desde sus comienzos en Málaga, las páginas de su boletín oficial del obispado, se hicieron eco del beneficio que aportaba la actividad

123 AMS BOAS 345 (1896) 398-400.

124 Cf. MARTÍNEZ ESTEBAN, Aceptar el poder constituido, Publicaciones de la Facultad de Teología "San Dámaso", Madrid, 2006, pp. 162-176, 423-428; ANDRÉS-GALLEGO, J., La política religiosa en España. 1889-1913, Editora Nacional, Madrid, 1975, p. 327.

125 Cf. RUIZ SÁNCHEZ, J. L., Prensa y propaganda católica (1832-1965), Editorial Universidad de Sevilla, Sevilla, 2002, pp. 47-62. 
de diversos centros por el territorio español ${ }^{126}$ : la Propaganda Católica de Palencia, con sus folletos sencillos y baratos, que popularizaba las buenas doctrinas; la biografía sobre D. Bosco (Don Bosco y su obra), publicada dentro de Lectura Popular, colección dirigida por Sardà ${ }^{127}$. Aplaudió también El Apostolado de la Prensa, establecido en Madrid, bajo la dirección del P. Garzón, y que comenzó a publicar La Lectura Dominical; hizo propaganda de los trabajos que llevaba a cabo $\mathrm{La}$ Lectura Popular de Orihuela ${ }^{128}$.

\subsubsection{Desde una defensa firme en el boletín oficial}

Por otra parte, su pluma no se detuvo para denunciar y condenar aquellos artículos y publicaciones que atacaban a la Iglesia y sus principios. En 1887 lo hizo contra la revista masónica La Estrella Flamígera ${ }^{129}$.

En Sevilla hizo otro tanto, en 1896, recién llegado, y fue esta vez, contra El Baluarte, diario de ideología republicana, que la había emprendido contra la Iglesia y personalmente contra él, desplegando una propaganda anticlerical de forma continuada ${ }^{130}$. Posteriormente, en 1898, lo hizo contra el semanario madrileño Vida Nueva ${ }^{131}$.

Incluimos en este mismo apartado, la publicación en el boletín diocesano, precedido de un comentario suyo, de los decretos generales de León XIII, sobre la prohibición y censura de libros, así como de la censura y denuncia de todos los escritos que venían en periódicos, revistas, hojas de volantes, etc. que nuestro autor consideraba como malas lecturas ${ }^{132}$.

\subsubsection{La manera de instruir desde el boletín diocesano}

A la hora de instruir a sus diocesanos, para la lectura de los periódicos decimonónicos, tampoco se detuvo su pluma. A modo de pastoral

\footnotetext{
126 Cf. AMS BOM 3 (1887) 102-103.

127 Cf. AMS BOM 8 (1887) 198-199.

128 Cf. AMS BOM 13 (1887) 184.

129 Cf. AMS BOM 13 (1887) 186.

130 Cf. AMS BOAS 340 (1896) 262-271.

131 Cf. AMS BOAS 393 (1898) 287.

132 Cf. AMS BOAS 413 (1899) 199-201; BOAS 442 (1899) 369-372; BOAS 433 (1900) 68-71.
} 
publicaba en el verano de 1891, diecinueve páginas que contenían su opinión al respecto. Sirva de muestra el texto siguiente:

"Ufana por extremo y engreída, está la prensa con el oficio y funciones que en nuestra sociedad desempeña; como que se tiene por un poder [...] ante el cual todos los demás poderes se inclinan, y al final a la postre, se venden y someten [...] Ni podemos asentir a la idea de que la opinión sea la Reina del mundo, cuando tan frecuentemente se extravía por preocupaciones y pasiones, cometiendo torpes yerros [...] ni aún convenimos en que el periodismo ejerza ministerio responsable cerca de esa soberbia [...] Debía el periodista, dada la elevadísima misión, que la prensa se atribuye [...] ser razón de consumada ciencia, en alto grado práctico, y de prudencia exquisita y maduro juicio [...] sin embargo, salvo honrosas excepciones, que nos complacemos en reconocer [...] periodista se hace en los tiempos presentes cualquiera, [...] La tolerancia de las autoridades al consentir publicaciones que atentan contra las normas más elementales del decoro y las buenas costumbres, y la actitud de quienes los compran contribuyendo a su sostén económico"133.

Hasta aquí, esta fue la manera que nuestro protagonista mantuvo como iniciativa para instruir a los laicos, sus diocesanos.

\subsection{Dos empresas que puso en marcha}

Cuando era arzobispo de Sevilla, con el fin de movilizar a los laicos sevillanos, puso en marcha dos empresas de carácter diocesano. Por orden cronológico, la primera fue el establecimiento de centros diocesanos de prensa católica (entonces"buena prensa") ${ }^{134}$. Distintos organismos diocesanos, se instituyeron, con el objeto de imprimir hojas y folletos de propaganda católica. En 1898, tras un ensayo en Sanlúcar de Barrameda, bajo el patrocinio de san José, se funda en Sevilla, la Asociación Diocesana para las Buenas Letras ${ }^{135}$. Esta,

133 AMS BOM 7 (1891) 178-196; cf. RUIZ SÁNCHEZ, J. L., Beato Marcelo Spinola y Maestre, cardenal Arzobispo de Sevilla, Servicio de Publicaciones del Ayuntamiento de Sevilla, Sevilla, 2002, p. 185.

134 Cf. CÁRCEL ORTÍ, V., Historia de la Iglesia en la España contemporánea: Siglos XIX y XX, Palabra, Madrid, 2002, pp. 121-135; ROMERO DOMÍNGUEZ, L. R., La buena prensa. Prensa Católica en Andalucía en la Restauración, Fundación Centro de Estudios Andaluces, Sevilla, 2009, pp. 28-85.

135 El estudio de las distintas etapas de esta asociación está publicado en: cf. RUIZ SÁNCHEZ, J. L., Periodismo católico en Sevilla. De la Asociación de la Buena Prensa a la Junta Nacional de Prensa Católica (1900-1925), Secretariado de Publicaciones de la Universidad de Sevilla, Sevilla, 2005, pp. 103-199. 
consistía, en el reparto gratuito de impresos morales, folletos y publicaciones católicas, en todas las parroquias de la ciudad, en los centros de obreros, en el hospital y en la cárcel. Entre sus dirigentes, además de Spínola a la cabeza, figuraban sacerdotes diocesanos, padres filipenses y laicos de alta instrucción; los cuales jugaban un papel fundamental. El objetivo de don Marcelo, era convertir las columnas de este periodismo, en verdaderos púlpitos de la verdad y la justicia evangélicas.

La otra empresa que puso en marcha nuestro beato, con el fin de movilizar a los laicos, fue la fundación del diario católico: El Correo de Andalucía ${ }^{136}$. Tenemos que decir al respecto, que esta empresa fue coetánea al papel desarrollado en pro de la Buena Prensa, pero ajena a ella. El 1 de febrero de 1899, comienza su andadura con un subtítulo: "diario católico de noticias"137. Hasta entonces, era el propio boletín oficial de la archidiócesis el que se encargaba de publicar las noticias de interés (locales, nacionales e internacionales) para los sacerdotes y católicos en general. Para el funcionamiento del periódico, se rodea de los mejores colaboradores, entre ellos encontramos al entonces rector del seminario, Modesto Abin; el magistral José Roca y Ponsa; y Rafael Sánchez, primer director del diario ${ }^{138}$. La primera editorial, con la que arranca el nuevo diario, es muy clarificadora, fue escrita por su censor y directivo, el canónigo Roca y Ponsa ${ }^{139}$. El diario respondía a la voz del papa, que reclamaba se multiplicase la prensa católica para

136 Cf. ROMERO DOMÍNGUEZ, L. R., La buena prensa. Prensa Católica en Andalucía en la Restauración, Fundación Centro de Estudios Andaluces, Sevilla, 2009, pp. 104-117; JAVIERRE, J. M., Don Marcelo de Sevilla, Ediciones Sígueme, Salamanca, 1992, p. 542.

137 Cf. GARCÍA MARTÍN, N., Vida de Don Marcelo Spínola y Maestre, Cardenal Arzobispo de Sevilla. Fundador de las Esclavas del Divino Corazón. Apuntes de la Postulación. Estudio sistemático y cronológico de su vida, Mecanografiadas y encuadernadas a mano. En Archivo Marcelo Spínola (al que en adelante nos referiremos como AMS) C D. 2; D. 2. 1. Sevilla, 1955, cap.VIII, p. 10.

138 Cf. MADRE ESPERANZA DEL CORAZÓN DE JESÚS, Vida del Emmo. y Rvmo. Sr. Cardenal Arzobispo de Sevilla, don Marcelo Spinola y Maestre, Sevilla, 1924, p. 453.

139 Sale hoy, por primera vez, El Correo de Andalucía, que ni es carlista ni integrista, sino eminentemente católico y noticiero. No será un periódico consagrado a la piedad, que para tanto no tenemos aliento; antes eminentemente noticiero, con una información local, regional, nacional y extranjera [...] Noticias de comercio, industria, artes, ciencia, agricultura, política; de todo lo que sea honesto y recreo [...] En cuanto a política no pertenecerá a ninguna de las agrupaciones en que los católicos españoles se dividen. No por esto pretende formar una agrupación más, líbrenos Dios de tentación semejante, aspira solo a trabajar a la sombra de la autoridad del prelado, para ofrecer 
contrarrestar la impiedad, el anticlericalismo y el fundamentalismo; como era el caso de Diario de Sevilla ${ }^{140}$, que sin ningún género de dudas, era de condición integrista.

La vinculación de don Marcelo con El Correo de Andalucía fue total: le pertenecía, como hizo ver años más tarde el administrador del rotativo ${ }^{141}$. Los comienzos del diario en sus primeros años fueron muy dificultosos (no terminaba de abrirse hueco entre las restantes publicaciones, los balances eran bastante negativos, la información era deficiente), aun así, la Iglesia de Sevilla, consiguió un triunfo al abrirse hueco con un medio de comunicación y propaganda propio, a las órdenes de su fundador y prelado, y hacer realidad en Sevilla el scripta scripti concurse nom impari ${ }^{142}$, y promover sus propias campañas regeneracionistas; como la de recabar apoyos por parte de la ciudadanía para los compromisos electorales de la Liga Católica ${ }^{143}$, de quien se erigió en portavoz; así como también, en definitiva, facilitar la regeneración de la sociedad desde posiciones cristianas. Tenemos que resaltar el papel que jugaron los laicos del arzobispado en sus primeros años en cuanto a sostenimiento del diario.

\section{SU IMPLICACIÓN EN LA PARTICIPACIÓN DE LOS CATÓLICOS EN LA VIDA PÚBLICA Y SU UNIÓN EN LA POLÍTICA}

\subsection{Prolegómenos}

La situación histórica, social y política en la que se desenvolvía la vida de los españoles de aquella época (finales del siglo XIX y comienzos del XX), para comprender la toma de posturas que don Marcelo adoptó en cuanto a la presencia de los católicos en la vida pública y su unión en la política.

a los hombres de bien un diario como la exigencia de los tiempos reclama, dentro de la verdad y la virtud.

(ROCAY PONSA, J.,"editorial” en El Correo de Andalucía n. ${ }^{\circ} 1$ [1899] p. 2).

140 Cf. RUIZ SÁNCHEZ, J. L., Política e Iglesia durante la Restauración. La Liga Católica de Sevilla (1901-1923), Diputación Provincial de Sevilla, Sevilla, 1994, pp. 133-137.

141 Cf. ROCAY PONSA, J., ("editorial”), en El Correo de Andalucía n. 42 (1902) p. 2.

142 Cf. RUIZ SÁNCHEZ, J. L., Política e Iglesia durante la Restauración. La Liga Católica de Sevilla (1901-1923), Diputación Provincial de Sevilla, Sevilla, 1994, pp. 231-239.

143 Cf. id., pp. 521-618. 
Spínola se quejaba de las divisiones que había entre los católicos, en cuanto a la política, dentro de la Iglesia ${ }^{144}$. Por una parte, los católicos integristas y su núcleo duro, que eran los carlistas; que sacaban de contexto las enseñanzas pontificias, al mismo tiempo, que la de sus obispos, llevando al extremo la moral cristiana, relegándola a un simple puritanismo; y se enfrentaban contra los que no pensaban como ellos, aislándose de la Iglesia, no queriendo participar en la vida eclesial. Por otra parte, los católicos, que bajo la apariencia de una tolerancia mentida, eran intransigentes con los que no adoptaban sus criterios, e iban ahondando de forma inconsciente en la división entre los católicos. Esta situación se convirtió en un problema endémico, que arrastraba España desde principio del siglo XIX, y que se conducía hasta el primer tercio del siglo $X^{145}$.

\subsection{Su implicación}

Como obispo, recomendaba a su presbiterio, se implicaran con preferencia, en que sus feligreses fueran instruidos de forma adecuada, a fin de que pudieran participar en la vida pública. Él no quería limitar su magisterio a recomendar a sus fieles que fueran buenos, sumisos, obedientes, limosneros... sino que también los instaba a cumplir las obligaciones que tienen como ciudadanos católicos ${ }^{146}$.

Los congresos católicos fueron uno de los instrumentos que la Iglesia puso en marcha para poner en movimiento a los católicos, teniendo por objetivo unificar los criterios entre la jerarquía eclesiástica y los laicos. En España, estas magnas asambleas, se celebraron entre

144 Cf. AMS BOM 12 (1890) Circular n. ${ }^{\circ}$ 487, 279-283.

145 Cf. AMS BOM 4 (1894) Circular n. ${ }^{\circ}$ 609, 105-109; ROBLES MUNOZ, C., "Católicos liberales. La Iglesia ante la Restauración (1875-1888)": Antología Anпua 35 (1988) pp. 418-428; ANDRÉS-GALLEGO, J., La política religiosa en España 1889-1913, Editora Nacional, Madrid, 1975, pp. 319-321; LABOA, J. M., El integrismo: un talante limitado y excluyente, Narcea, Madrid, 1985, pp. 65-94.

146 Entre sus escritos hemos seleccionado esta cita, que no puede ser más clarificadora:

No ya solo como individuos particulares, sino como miembros de la sociedad cristiana, y aun como ciudadanos, pues bajo estos múltiples aspectos están sujetos a la moral católica, cuya jurisdicción a todas partes alcanza [...] No para derribar o alcanzar tronos, no para apoyar a determinados partidos políticos, sino para defender la causa sagrada de Dios.

(AMS BOAS 474 [1901] 127). 
1889 y 1902, pero que debido a la gran división interna en la Iglesia (entre el episcopado y de los católicos entre sî), tuvieron un escaso desarrollo y menores frutos, a diferencia de los países de nuestro entorno (Italia, Francia).

Nuestro personaje, a diferencia de otros prelados, fue un destacado militante en favor de estos congresos. Fue el único obispo de toda Andalucía que asistió al de Zaragoza en 1890147; el Congreso terminó $^{148} \sin$ disipar los enfrentamientos ${ }^{149}$. Él fue siempre muy crítico con los resultados tan pobres que se obtenían de estas reuniones, según su juicio ${ }^{150}$.

Del IV Congreso celebrado en Tarragona en 1894, escribe en las páginas del boletín oficial malacitano y lo hace sin andarse por las ramas:

"Hablemos claro. Tenemos por católicos excelentes a los que se dicen hoy íntegros o integristas [...] así no podemos de sentir con toda nuestra alma, que llevados de un puritanismo, exagerado a nuestro entender, se aísle, se separen de los que no piensan como ellos, [...] Tenemos también por buenos católicos a otros, pero nos causa pena observar [...] la inconsciente labor a que se entregan de ahondar la división, en lugar de afanarse para acortar distancias [...] Por estos caminos no se va a ninguna parte [...]"151.

En 1892, para el que le encargaron un discurso muy comprometido: Deberes y derechos de los católicos en el orden político, y medios prácticos de cumplir los usos y ejercitar los otros para evitar

147 En su viaje a Zaragoza, escribe a su hermana Rosario desde Madrid:

Aunque pensé no vestir la sotana morada hasta llegar a Zaragoza he tenido que quebrantar el propósito, pues el Nuncio había manifestado deseos de verme y no tuve más remedio que ir al Palacio de la Nunciatura.

(Madrid 3 de octubre de 1890), en: AMS F. 85, p. 1.

148 De nuevo en una carta dirigida a su hermana Rosario comenta lo siguiente:"Hoy concluye el Congreso, sin haber dejado satisfecho a ninguno. Yo no sé si con razón o sin ella; pero todos se quejan". (Zaragoza 10 de octubre de 1890) en: F. 85, p. 4.

149 Días antes de finalizar el Congreso, nuestro autor escribe como de costumbre a su hermana Rosario diciéndole:

[...] los ánimos están bastante excitados. Los hombres del Siglo Futuro se quejan de que no les han tratado como debieran y entiendo que no les falta razón; los otros creen, por el contrario, que han hecho mucho; se han anunciado protestas, retiradas y no sé qué más, aunque al fin tales propósitos no se han llevado a cabo.

(Zaragoza 8 de octubre de 1890), en: AMS F. 85, p. 11.

150 Cf. AMS BOM 12 (1890) 487-488.

151 AMS BOM 4 (1894) Circular n. ${ }^{\circ}$ 609, 105-106. 
completa apostasía de las sociedades modernas ${ }^{152}$. Fue testigo de las sesiones públicas, el templo de El Salvador de la capital hispalense; y el día 21 de octubre pronunció su discurso. Pero las dificultades no radicaban en los principios ideológicos, dadas las disposiciones pontificias, que facilitaban llegar a acuerdos; las dificultades estaban en los procedimientos, pues era necesario pensar, medir y valorar las múltiples razones de lugar, tiempo y circunstancia; además había que tener en cuenta los ataques que se producían desde la impiedad; que estaban dispuestos por todos los medios a impedir cualquier organización de esta naturaleza entre los católicos. Nuestro personaje nos viene a decir en su discurso, que había tres cuestiones que clasificar: la íntima relación entre el orden político y el religioso, la necesidad de acabar con la indiferencia de los católicos en los asuntos políti$\cos \mathrm{y}$, resueltas estas dos cuestiones, urgentemente y de inmediato, dada la apostasía de las naciones. En él también hace alusión a los llamamientos que León XIII hace para conseguir la unión de los católicos en España en el terreno político ${ }^{153}$, siguiendo las directrices del episcopado, formando un cuerpo compacto y disciplinado, para hacer eficaz la participación en todos los ámbitos de decisión político, y por otro lado, era necesaria la unidad entre la prensa católica, para que en la única bandera de la caridad, desaparezcan las divisiones y guerras difamatorias que se producían en su interior.

Pero nada se avanzó en estas fechas en el terreno de la unión de los católicos en España, por los motivos que hemos anotado anteriormente; los distintos proyectos puestos en marcha: Unión Católica, Asociación de Católicos, etc.; terminaron en un fracaso ${ }^{154}$. En definitiva, aquello que León XIII vino a llamar en 1901"democracia cristiana" o acción social católica. En aquella España finisecular, la raíz y piedra angular del problema, era la desunión dentro de la Je-

152 Este discurso fue el primero pronunciado en la tercera Sesión Pública. Cf. Crónicas del Tercer Congreso Católico Nacional Español. Discursos pronunciados en las sesiones públicas y reseñas de las memorias y trabajos presentados en las sesiones de dicha Asamblea Nacional celebrada en Sevilla en octubre de 1892 (Sevilla 1893) pp. 305-336.

153 Cf. CÁRCEL ORTÍ, V., León XIII y los católicos españoles, Eunsa, Madrid, 1978, pp. 19-76.

154 Cf. MAGAZ FERNÁNDEZ, J. M., La Unión Católica (1881-1885), Publicaciones del Instituto Español de Historia eclesiástica, Roma, 1990, pp. 320-342. 
rarquía ${ }^{155}$, en cuanto que no tenían una idea nítida del sentido auténtico en que la Iglesia había condenado el liberalismo ${ }^{156}$; pudiendo de esta manera hablar todos de lo mismo en semejantes términos. Don Marcelo poseía una gran formación jurídica ${ }^{157}$, y le surgían dudas que compartía con otros obispos sobre la situación del liberalismo en nuestra nación. Cuando era arzobispo de Sevilla, reclamaba al Nuncio sobre una pregunta que le formulaba: “ ¿Pueden los verdaderos católicos afiliarse o continuar afiliados a los partidos liberales más o menos avanzados?". En esta misma carta, a la espera de su contestación autorizada, señalaba la existencia de personalidades en los partidos liberales que eran católicos y practicantes en la religión, y que desde sus puestos más o menos altos, hacen el bien y evitan otros males ${ }^{158}$. Entre estos, se refería a autoridades provinciales y aun a algunos ministros que llevaban una vida ejemplar. Nuestro personaje, argumentaba en su carta al Nuncio que:"Alejar a estos hombres de los bandos en que militan, sería abrir ancha puerta a los enemigos de Dios o a sus falsos amigos".

Posteriormente, en 1901 escribe en las páginas del boletín oficial del arzobispado, en las que refleja una mayor clarificación conceptual diciendo:

"Creemos que las formas de gobierno son de suyo indiferentes, pudiendo aceptar los católicos sin menoscabo de su fe, lo mismo las monarquías que las repúblicas, [...] pero hay un espíritu, que suele introducirse tanto en las repúblicas como en las monarquías, y que se puede definir como: la independencia del Estado de todo elemento divino [...] Respecto a este espíritu, que es el liberalismo con sus múltiples grados [...] nuestro criterio para juzgarlo es el Syllabus y las decisiones y aclaraciones repetidas de Pío IX y León XIII"159.

Spínola, tenía claro el fracaso a nivel nacional de toda tentativa, por lo que él dedicó todas sus fuerzas a nivel diocesano. Dos cuestio-

155 Cf. MARTÍNEZ ESTEBAN, A., El Cardenal Sancha en la encrucijada de la Iglesia española, Vision Libros, Madrid, 2013, pp. 276-287.

156 Cf. MARTÍNEZ ESTEBAN, A., Aceptar el poder constituido, Publicaciones de la Facultad de Teología"San Dámaso", Madrid, 2006, p. 369.

157 Todo su expediente académico, que avala lo dicho arriba, se encuentra en: AMS C C. 2.2.

158 La copia de esta carta-informe se encuentra en: AMS C C. 1.1.

159 AMS BOAS 482 (1901) “Una aclaración importante”, 329-330. 
nes fundamentales consigue en la archidiócesis hispalense: someter a sus dictados la llamada prensa católica, y aglutinar a los católicos de distintas tendencias en un proyecto común, fundamentalmente en lo político: la Liga Católica ${ }^{160}$.

En 1905, el 8 de julio escribe de nuevo en las páginas del boletín oficial del arzobispado en referencia a la reacción que causó el contenido referente a las Ligas Católicas del boletín del 31 de mayo:

"Aquella exhortación, que contenía algunas apreciaciones sobre los motivos que traen en desunión a los católicos españoles, dio causa a un periódico de Madrid para escribir unos artículos, en que no quedábamos por cierto muy bien parados [...] lanzaba contra nosotros graves acusaciones, porque afirmaba lo primero que no habíamos interpretado bien el pensamiento del Papa al instituir y fomentar la Liga Católica de Sevilla; que habíamos además cometido un abuso de autoridad, [...] y que metiéndonos en un campo que nos estaba vedado, el cual es el de la política, y habíamos por último errado el camino, quitando o intentando quitar a la Iglesia los baluartes que la defienden, en lugar de cubrirla con invulnerable escudo [...] No podíamos quedar bajo el peso de acusaciones tan tremendas, y acudimos a Roma. [...] Nos limitamos a enviar al Emmo. Sr. Cardenal Secretario de Estado de Su Santidad nuestro escrito y los artículos, que hasta entonces había publicado el periódico aludido; rogando a Su Eminencia que, si no lo creía inoportuno, pidiese alVicario de Cristo una palabra, que nos aquietase, que disipase nuestros temores sobre si habíamos o no interpretado mal su pensamiento.

El Papa no se ha contentado con respondernos afirmativamente por medio de su Secretario de Estado, sino que nos ha dirigido la carta, que nos apresuramos a dar a conocer al público [...]

Lean los miembros de la Liga ese documento, léanlo nuestros diocesanos, léanlo los que componen la Asociación de la Buena prensa, léalo España toda, porque con España habla Su Santidad, y ante su palabra inclinemos respetuoso la frente para obedecerlo"161.

Más tarde publica la carta del papa Pío X, del 27 de junio de 1905, dirigida a la Liga Católica de Sevilla:

“Deber nuestro es comunicarnos con la Liga Católica de Sevilla, [...] a fin de marcarle, [...] los derroteros que ha de seguir, y que han merecido la aprobación de Su Santidad.

160 Cf. MARTÍN-TEJEDOR, J., “La Liga Católica de Sevilla (1901-1923)”: Hispania Sacra vol. 49 n. ${ }^{\circ} 99$ (1997) pp. 125-228.

161 Estas palabras fueron dirigidas el 7 de julio de 1905. (AMS BOAS 571 [1905] 5-7). 
Empecemos por las personas llamadas a ser miembros de la Liga. Todos los católicos de buena voluntad caben en ella [...]

Ni debe perderse de vista que el fin de las Ligas no es el triunfo de una dinastía, ni de un régimen político, ni de una parcialidad, sea de la clase que fuere, sino la defensa de nuestra fe. Si las Ligas envían Concejales a los Municipios es para que allí apoyen las soluciones más favorables a la religión; si suelen no estarse ociosas cuando se eligen los representantes, que han de llevar la voz de los pueblos a los Parlamentos, es para que al discutirse asuntos en que la Iglesia se haya interesada, tenga ésta quien haga valer sus derechos; en suma, para las Ligas no hay más que católicos, ni otra cosa quieren ni se proponen si no que Jesucristo no esté desamparado, sino antes bien, que en todas partes cuente con abogados, que luchen por su causa $[\ldots]$

Lo cual no impide que sea muy dilatado el campo de acción de las Ligas, pues la vindicación de la doctrina, su conservación libre de toda mezcla extraña, su difusión entre los que no la conocen; el imperio de la moral católica en la conciencia privada y en la conciencia pública; la guarda de los derechos de la Iglesia en el hogar, en la escuela, en el pueblo y hasta en el Estado; el mejoramiento de la clase obrera, y su emancipación del yugo, a que intentan sujetarla falsos amigos que se intitulan sus liberadores, cuando en realidad son sus opresores y tiranos; la propagación de la caridad en las relaciones de los hombres, del grande con el pequeño, del rico con el pobre, del patrono con el obrero, del que manda con el súbdito: ved el círculo luminoso que abarcan las Ligas Católicas como parte, y no escasa, de eso que ha apellidado nuestro Santo Padre, la acción popular cristiana [...]"162.

Como se puede desprender de estas letras papales, nuestro protagonista, consiguió afianzar con éxito este instrumento para hacer llegar la voz de los católicos a "los púlpitos" civiles y públicos: ayuntamientos, diputaciones provinciales, Parlamento, etc.; y este era: la Liga Católica de Sevilla, en la que queda de manifiesto el extraordinario papel pionero que desempeñó nuestro beato, en la movilización de los fieles cristianos laicos en la vida pública, siguiendo los planteamientos del papa León XIII y de la entonces emergente Doctrina Social de la Iglesia.

Su trayectoria, no solo fue desarrollándose, como hemos visto, con grandes logros, sino que para colmo, recibe ante toda la Jerarquía Española, el respaldo del sumo pontífice.

162 AMS BOAS 577 (1905) 241-243. 


\section{CONCLUSIÓN}

Hemos hecho un adecuado recorrido, abordando los diversos modos particulares de ejercer su ministerio ordenado. Desde la centralidad que ocupa la espiritualidad del Sagrado Corazón de Jesús, que se haya de manera omnipresente y permanente en todo el ejercicio de su ministerio ordenado; la extensa andadura del beato Spínola en la defensa de la cuestión social y particularmente del mundo obrero, con el fin de hacer presente el mensaje evangélico como la única solución a todas las injusticias sociales; la fecunda actividad en la política de nuestro purpurado, en su condición de Senador del Reino y desde la tribuna de dicha Cámara Alta, en defensa de la Iglesia y sus derechos; hemos desarrollado también de manera proporcionada, su actividad en el ámbito de la organización de la propaganda católica y la prensa, y su fundación del diario El Correo de Andalucía; con un único objetivo: defender los planteamientos de la Iglesia frente al liberalismo y su propaganda, que estaban socavando los principios morales del catolicismo; y finalmente hemos puesto de manifiesto las posturas e iniciativas que adoptó nuestro beato, en cuanto a la unión de los católicos en la cuestión de la política, así como en la participación de los mismos en la vida pública, fundamentalmente a través de la Liga Católica que crea en Sevilla.

Con este artículo estimamos haber conseguido demostrar, que el ejercicio de las virtudes, su fina inteligencia y capacidades humanas, le llevaron a utilizar de forma prudente y sabia, todos los resortes e instrumentos que tenía a su alcance, con una única meta: alcanzar su propia santidad y la santificación del pueblo de Dios; de aquí, que hayamos podido estudiar y poner en valor, la originalidad en el desempeño del ministerio ordenado del cardenal Spínola. 